\title{
Model-Based Control of a Nonlinear Aircraft Engine Simulation using an Optimal Tuner Kalman Filter Approach
}

\author{
Joseph W. Connolly* \\ NASA Glenn Research Center, \\ Cleveland, $\mathrm{OH}$ 44135, USA \\ Jeffrey T. Csank ${ }^{\dagger}$ \\ NASA Glenn Research Center, \\ Cleveland, $\mathrm{OH}$ 44135, USA \\ Amy Chicatelli ${ }^{\ddagger}$ \\ Vantage Partners LLC, Brook Park, OH 44142, USA \\ Jacob Kilver ${ }^{\S}$ \\ Ohio State University, Columbus, OH 43210, USA
}

\begin{abstract}
This paper covers the development of a model-based engine control (MBEC) methodology featuring a self tuning on-board model applied to an aircraft turbofan engine simulation. Here, the Commercial Modular Aero-Propulsion System Simulation 40,000 (CMAPSS40k) serves as the MBEC application engine. CMAPSS40k is capable of modeling realistic engine performance, allowing for a verification of the MBEC over a wide range of operating points. The on-board model is a piece-wise linear model derived from CMAPSS40k and updated using an optimal tuner Kalman Filter (OTKF) estimation routine, which enables the on-board model to self-tune to account for engine performance variations. The focus here is on developing a methodology for MBEC with direct control of estimated parameters of interest such as thrust and stall margins. Investigations using the MBEC to provide a stall margin limit for the controller protection logic are presented that could provide benefits over a simple acceleration schedule that is currently used in traditional engine control architectures.
\end{abstract}

\section{Nomenclature}

\begin{tabular}{|c|c|c|c|}
\hline CMAPSS40k & $\begin{array}{l}\text { Commercial modular aero-propulsion } \\
\text { system simulation } 40,000\end{array}$ & Ps3 & $\begin{array}{l}\text { High pressure compressor static } \\
\text { discharge pressure }\end{array}$ \\
\hline EoL & End of life & $R U$ & Ratio unit $\left(\frac{W_{f}}{\mathrm{Ps} 3}\right)$ decceleration limiter \\
\hline EPR & Engine pressure ratio & $\mathrm{SM}$ & Stall margin \\
\hline $\mathrm{F}_{\mathrm{NET}}$ & Engine net thrust & $\mathrm{T} 3$ & High pressure compressor discharge \\
\hline FAA & Federal aviation administration & & temperature \\
\hline $\mathrm{HPC}$ & High pressure compressor & $\mathrm{T} 50$ & Low pressure turbine exit temperature \\
\hline MBEC & Model based engine control & $\mathrm{T} 40$ & Combustor exit temperature \\
\hline $\mathrm{N}_{\mathrm{c}}$ & Core rotational speed & VBV & Variable bleed valve \\
\hline $\mathrm{N}_{\mathrm{f}}$ & Fan rotational speed & VSV & Variable stator vane \\
\hline OTKF & Optimal tuner Kalman Filter & $W_{f}$ & Fuel flow \\
\hline P50 & Low pressure turbine exit pressure & $e^{J}$ & Error \\
\hline
\end{tabular}

PI Proportional integral controller

PLA Power lever angle

\footnotetext{
*Aerospace Engineer, Controls and Dynamics Branch, 21000 Brookpark Rd., 77-1, AIAA Senior Member

$\dagger$ Aerospace Engineer, Controls and Dynamics Branch, 21000 Brookpark Rd., 77-1, AIAA Member

$¥$ Aerospace Engineer, Controls and Dynamics Branch, 3000 Aerospace Parkway VPL-3, AIAA Senior Member

$\S$ Student, Electrical Engineering Department
} 


\section{Introduction}

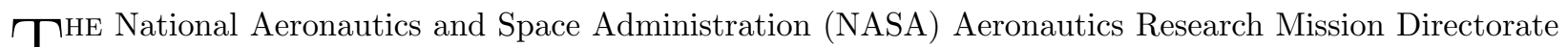
aims to develop technologies to improve the safety and fuel efficiency of commercial aircraft. Conservation of fuel in transportation systems has been identified as a national goal to reduce harmful emissions and is recognized as a responsibility that requires government involvement in order to be achieved. NASA has documented that reduction in air pollution and operational costs can be accomplished by creating technologies that reduce the following: drag, engine-specific fuel consumption and aircraft weight. ${ }^{1}$ Modelbased engine control (MBEC) is being developed as one of the advanced engine control system methodologies to improve turbofan engine efficiency. In addition, MBEC has potential to provide performance enhancement to transient turbofan engine responses.

In current engine control architectures, the typical design approach is to regulate a measurable variable such as fan shaft speed (Nf) or engine pressure ratio (EPR), which is correlated with thrust. This is done since engine thrust is not a measurable parameter from typical on-board engine sensors. Additionally, limits on allowable fuel flow are imposed based on a conservative approach to maintain adequate stall margin (SM) for safe operation of the engine throughout its life. This approach results in less efficient engine operation and leads to variations in the engine throttle to thrust response with engine deterioration. As an engine deteriorates with usage, the same throttle setting results in slightly different thrust because the relationship of the regulated variable (Nf or EPR) to thrust changes with engine aging.

MBEC will allow operation with less conservative operability margins, since operability margins discussed in this paper are currently designed to an end of life (EoL) engine, whereas an on-board model can provide a more accurate margin for the actual condition of the engine. The reduction in the operability margins for newer engines through the use of direct stall margin estimation protection logic can increase fuel efficiency. A stall margin limiter can be developed to ensure that a lower stall margin threshold can be used for developing a new operating line while maintaining safe operation during transient changes. By making modifications to the operating line, the goal of obtaining efficiency gains can be realized. The longer term pay-off of this research is to have a personalized control for each specific engine, which adapts to the actual condition of the engine to not only maintain more efficient operation throughout its lifetime, but also increase its useful operating life.

A MBEC architecture is comprised of three main components; first an engine or "truth" model, second an on-board model designed to provide real-time estimates of desired unmeasured parameters, and last a controller with limit protection logic. For the simulation study presented in this paper, the Commercial Modular Aero-Propulsion System Simulation 40,000 (CMAPSS40k) ${ }^{2}$ will serve as the engine that MBEC is applied to, an optimal tuner Kalman Filter (OTKF) will serve as the on-board model providing estimates of thrust and stall margin, and finally a thrust controller with stall margin protection is developed.

This paper builds upon previous work done by the authors using a linear analysis based on a single operating condition at cruise. ${ }^{3}$ The focus in this paper is on the development of a MBEC controller capable of being used throughout the flight envelope and during large transients. The following sections of this paper will discuss a traditional engine control architecture, the MBEC architecture, application of MBEC to CMAPSS40k results for the closed-loop MBEC thrust control with stall margin protection logic, comparisons of a baseline control to MBEC control, future work, and conclusions.

\section{Traditional Control Architecture}

A traditional control architecture for a turbofan engine equipped with a full authority digital engine control is shown in Fig. 1. Turbofan engine controllers are designed to regulate a measurable variable such as $\mathrm{N}_{\mathrm{f}}$ or EPR, which is correlated with thrust. The main interface between the pilot and the control system is the power lever angle (PLA) or throttle, which is used by the controller to set a required $\mathrm{N}_{\mathrm{f}}$ or EPR command. Traditional control design is restricted to these parameters due to the sensors and actuators that are implemented in practice. The measured $\mathrm{N}_{\mathrm{f}}$ or EPR is subtracted from the command set point to create an error signal that goes to the controller to determine a fuel flow $\left(W_{f}\right)$. Protection logic limits the commanded fuel flow to provide safe operation of the engine. Finally, the fuel flow signal is sent to the fuel metering valve. As mentioned previously, the traditional approach can result in less efficient engine operation due to engine-to-engine variations in the throttle to thrust response due to the operability margins being designed for an end-of-life engine, which are more conservative.

For safety and operability, protection logic is used to regulate excessive transients and operating conditions 


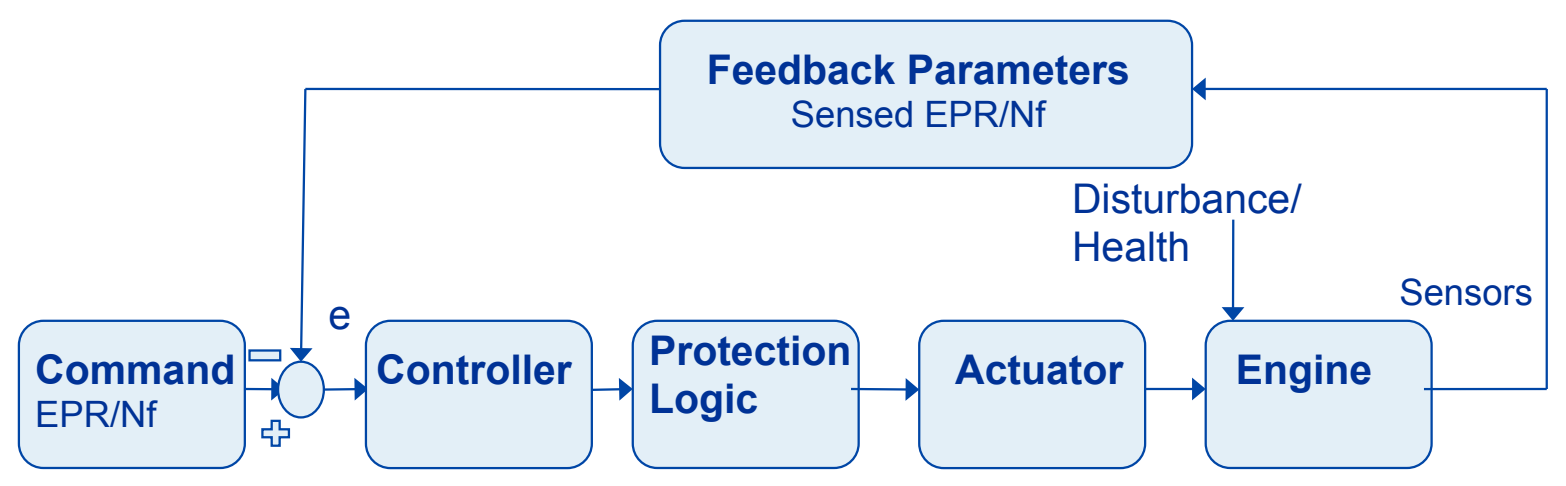

Figure 1. Traditional full authority digital controller diagram.

that could lead to stall or other engine failures, shown in Fig. 2. This is done by monitoring sensed parameters for engine shafts' acceleration, combustor pressure, maximum shaft speeds, and the ratio of $W_{f}$ to compressor discharge static pressure. There is a selection process using a min/max approach to determine the final $W_{f}$ signal that is provided to the fuel metering valve. While all of these limiters are used in traditional aircraft engine control logic, the primary interest in this study is high pressure compressor (HPC) stall margin, and therefore much of the rest of the paper will be focused on the estimation and control of this parameter during engine transients.

\section{Model-Based Engine Control Architecture}

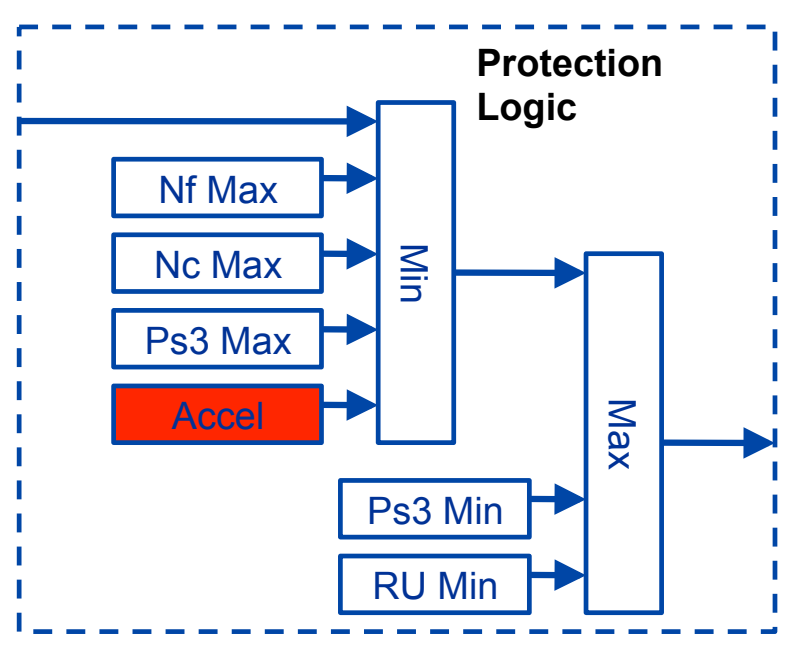

Figure 2. Protection logic limiters that limit the fuel flow based on prescribed operability margins.
In the aircraft engine research community, MBEC is widely recognized as a means to provide the necessary improved efficiency to reduce enginespecific fuel consumption. ${ }^{4-7}$ Although MBEC research has been ongoing for many years by organizations such as General Electric, ${ }^{8,9}$ Pratt and Whitney ${ }^{10}$ and others, ${ }^{11-13}$ one of the stumbling blocks has been the accuracy of the on-board model as the engine degrades with usage. Typically, engine degradation through aging is captured in engine models through health parameters, which are variables such as efficiency and flow capacity that represent performance deterioration within each major rotating component of the engine. The challenge comes about because typically the number of sensors available to update the on-board model to reflect the effects of engine performance deterioration, is less than the number of unknown health parameters. In other MBEC research done to date, a subset of these health parameters equal to the number of available sensors, referred to as tuning parameters, is used to update the on-board model. Although this approach results in good model estimates of the measured variables, it does not necessarily guarantee a good estimate of the unmeasured variables such as thrust and stall margin.

A general schematic of the MBEC architecture applied in this study is shown in Fig. 3. This architecture contains an engine simulation, an on-board model with an associated tracking filter for estimating unmeasured parameters, and a controller with protection logic. In MBEC, the $\mathrm{N}_{\mathrm{f}}$ or EPR regulation is replaced by regulation of net thrust (Fnet), and the acceleration protection limit shown in red of Fig. 2 is replaced by a direct HPC SM limiter. The thrust and limit controllers are designed as simple proportional integral (PI) controllers, which is consistent with PI control design strategies applied in traditional control architectures. The protection logic uses a min/max logic to provide an appropriate fuel flow command to the actuator. Within the on-board self-tuning engine model, an OTKF estimation routine is used to tune the on-board 


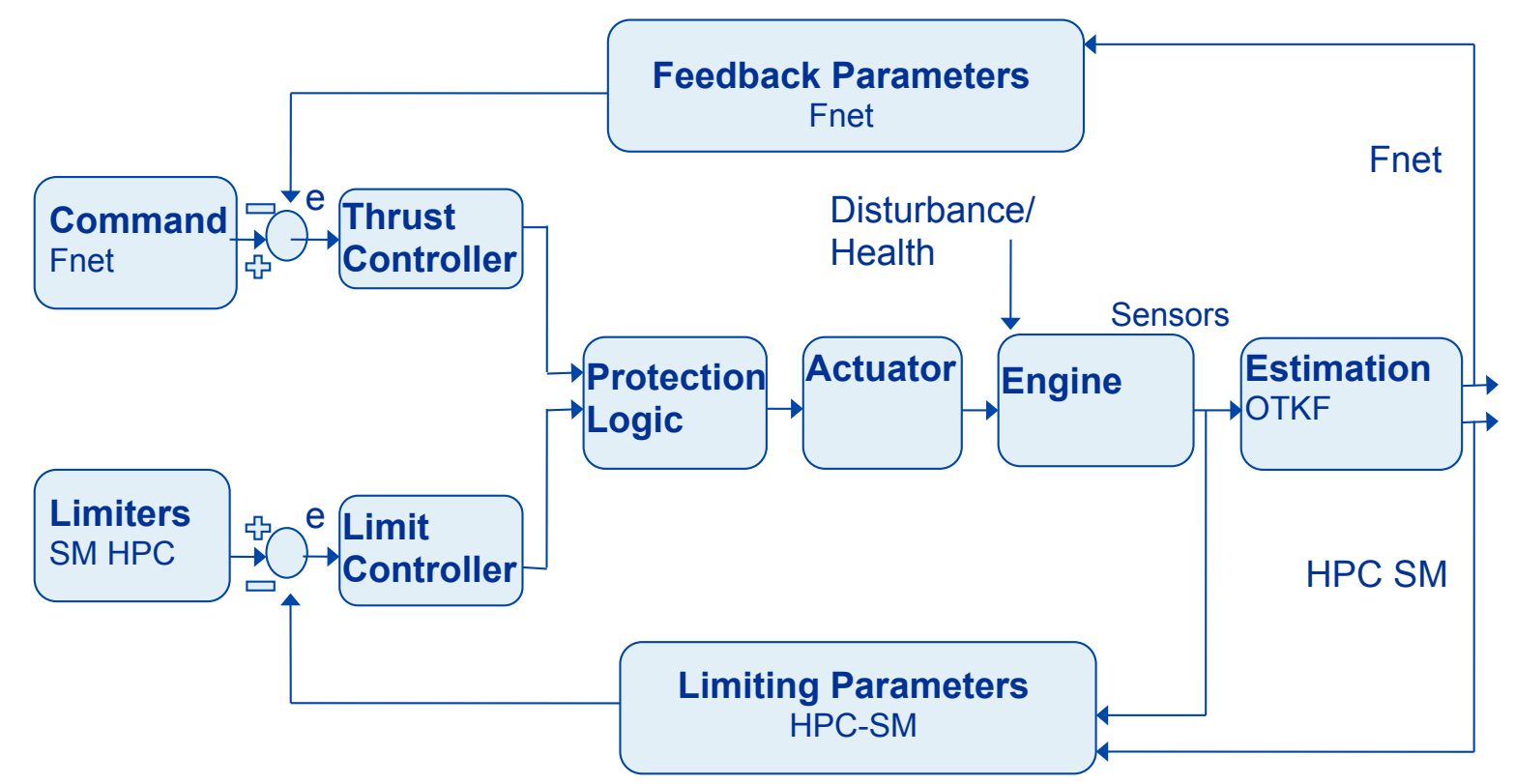

Figure 3. MBEC engine control model architecture.

model to the current engine condition. The OTKF is based on work performed by Simon, ${ }^{14}$ including its follow-on algorithm development. For the MBEC design, the control feedback parameters are not directly sensed, but are instead estimated by the OTKF. The following subsections will provide details about the on-board engine model and OTKF, the controller, and protection logic.

\section{Optimal tuner Kalman Filter}

Through research done under NASA's Aviation Safety Program, the OTKF approach has been developed to select tuning parameters that minimize the Kalman Filter mean squared estimation error in the unmeasured variables of interest. ${ }^{14}$ Developing a MBEC methodology around this OTKF approach provides the capability to overcome the inadequacies of past approaches and makes it practical to achieve the potential benefits of MBEC. Given the updated tuning parameters, a new control methodology can be implemented for directly controlling on thrust instead of $\mathrm{N}_{\mathrm{f}}$ or EPR. The OTKF uses a traditional set of engine sensors to provide estimates of non-sensed parameters such as stall margin and thrust.

The OTKF approach provides an optimal its is designing limiters and operating schedules.

\begin{tabular}{|l|c|}
\hline Debit Due To & $\%$ \\
\hline Engine to Engine Variation & $4.0 \%$ \\
\hline Reynolds Number Effects & $1.0 \%$ \\
\hline Working Line Deterioration & $2.0 \%$ \\
\hline Stall Line Deterioration & $4.0 \%$ \\
\hline Transient Allowance & $12.0 \%$ \\
\hline Surge Margin Required & $\mathbf{2 3} \%$ \\
\hline
\end{tabular}

Table 1. Stall margin stack up used for operability lim-

Kalman Filter that is calculated based on a global optimization routine for the estimated parameters of interest at operating points spanning the flight envelope. This optimization process can take on the order of tens of minutes, but only needs to be done once during the design phase of the OTKF.

\section{MBEC development}

Given the engine and on-board engine estimation elements developed, a thrust controller and stall margin protection logic can be developed over the full flight envelope to obtain the overall MBEC architecture. In Fig. 3 the MBEC simulation block diagram is illustrated. The thrust controller is directly closed around the estimated thrust and stall margin information is provided to the controller protection logic allowing for a reduction in the conservative margins providing improved efficiency of the turbofan engine. 
The reduction in the operability margins for newer engines through the use of direct stall margin estimation protection logic has the potential to increase fuel efficiency. The focus for this study is on using MBEC to improve the protection logic for the HPC SM as it plays an important role in designing the engine operating line. Table 1 shows a typical stack up of the effects considered in establishing the amount of compressor stall margin that the controller should be designed to maintain. ${ }^{15}$ Given this SM stack up a baseline engine control will have a steady state operating condition designed to have approximately a $23 \%$ margin. Several of the SM effects, or debits, are due to engine-to-engine variation or deterioration. Through MBEC, a stall margin limiter can be developed to ensure that a lower stall margin threshold can be used for developing a new operating line while maintaining safe operation during transient changes. The potential new operating line development is illustrated in Fig. 4 for the HPC map. The red line represents the stall line, the cyan line a notional baseline operating line, and the magenta a potential operating line with reduced stall margin. If perfect estimation of engine deterioration could be obtained, then the SM from Table 1 shows that only a $13 \%$ margin would be required to account for the Reynolds number and transient operation. The operating line redesign space is then illustrated in Fig. 4 between the two plotted operating lines. By making modifications to the operating line, the goal of obtaining efficiency gains can be realized through the potential higher efficiency closer to the stall line.

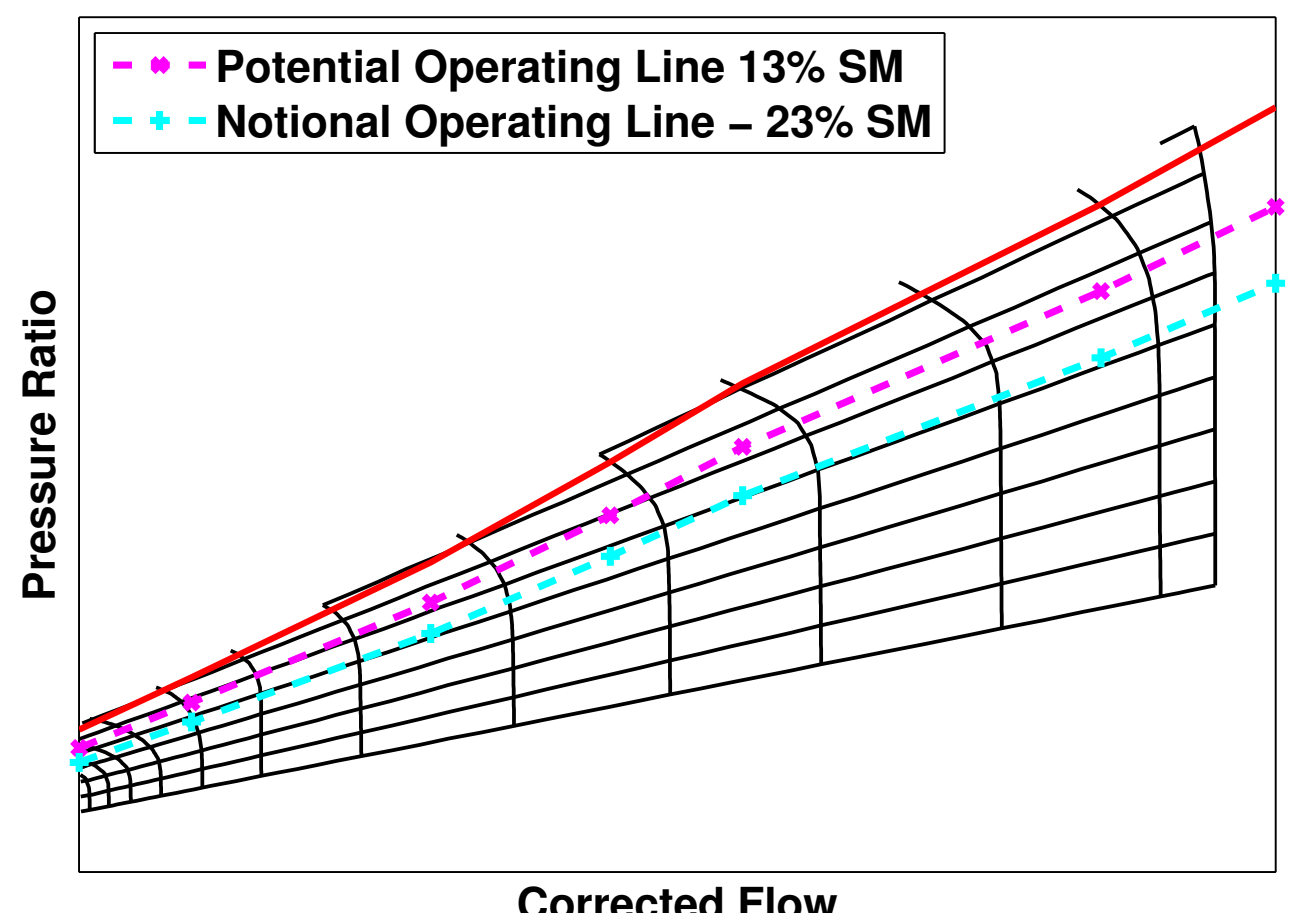

Figure 4. HPC generic compressor map.

The MBEC architecture accepts changes in PLA and converts them to changes in the thrust set point. The thrust controller then uses the error signal to send the fuel flow command to the fuel metering valve actuator. The engine responds to the controller commands and health condition disturbances, and outputs the typical sensed parameters to the OTKF and the controller protection logic. The OTKF then provides an estimate of thrust and stall margin. The overall MBEC architecture is the same as the linear point design MBEC model developed previously, with the primary difference being the piecewise linear scheduling of control gains that allow for operation throughout the operating envelope. ${ }^{3}$ The MBEC controllers mimics the typical PI design for the baseline controller and protection logic to provide a fair comparison between the two methodologies. 


\section{Application of MBEC to CMAPSS40k simulation}

In this study, the CMAPSS40k simulation is used to represent the engine. The CMAPSS40k simulation is a 40,000 lbf class turbofan engine simulation that is specifically designed for the development and testing of control algorithms. The simulation provides realistic transient engine responses and is capable of executing faster than real time. Baseline controllers using EPR and $\mathrm{N}_{\mathrm{f}}$ are provided in CMAPSS40k, along with protection logic similar to that shown in Fig. 2. For the CMAPSS40k simulation the controllers and limiters are designed as a PI control with integrator windup protection. ${ }^{16}$ CMAPSS40k, in addition to controlling the fuel flow schedules the variable stator vane (VSV), and variable bleed valve (VBV).

The model contains a typical suite of sensors for turbofan engine control architectures, which includes:

1. $\mathrm{N}_{\mathrm{c}}$, core speed

2. $\mathrm{N}_{\mathrm{f}}$, fan speed

3. Ps3, high pressure compressor discharge static pressure

4. T3, high pressure compressor discharge temperature

5. T50, low pressure turbine exit temperature

6. P50, low pressure turbine exit pressure

The CMAPSS40k simulation contains a fleet average profile of engine deterioration versus number of flight cycles. By changing the health parameters based on the percent deterioration of the engine, various stages of the engine life cycle can be simulated. To account for deterioration, the efficiency and flow capacity are modified in each of the following engine components: fan, low pressure compressor, high pressure compressor, high pressure turbine, and low pressure turbine.

For the optimal tuner estimation the six control sensors listed above are used. A total of ten health parameters and six sensors represents an underdetermined estimation problem thus illustrating the need for the OTKF approach. The on-board model is a piecewise linear time-invariant state space system developed from CMAPSS40k at an altitude from 0 to 40,000 ft in steps of 20,000 ft, Mach number from 0 to 0.8 in steps of 0.2 , and corrected fan speed from 1200 to $4200 \mathrm{rpm}$ in steps of $400 \mathrm{rpm}$. The piecewise linear model is used to establish the Kalman Filter estimation updates based on sensor inputs. The state vector for the state space model consists of fan and core speeds, and the control input is the fuel flow, VSV, and VBV. The estimated parameters for this study are the values of thrust, HPC stall margin, and combustor exit temperature, T40.

\section{Results}

The simulation results demonstrate the MBEC architecture using a thrust controller and stall margin protection logic at representative cruise and takeoff operating conditions. The cruise condition is for 30,000 $\mathrm{ft}$ altitude, Mach 0.7, and PLA of $60^{\circ}$, while the takeoff condition simulates a transient of going from idle to full power at sea level static conditions. The results shown will first focus on the MBEC controller and the estimation errors obtained, then illustrate the stall margin protection logic compared to the baseline $\mathrm{N}_{\mathrm{f}} / \mathrm{EPR}$ controller and acceleration limiter, and finally look at potential benefits of the MBEC architecture during a fan fault. As mentioned earlier, the major benefit of MBEC is in being able to operate at steady state with a reduced stall margin, which requires redesign of the steady state operating line. This aspect is not addressed in the current work. The focus of the current work is to investigate the feasibility of MBEC to provide safe operation throughout the operating envelope with comparable performance to the baseline control.

\section{MBEC controller and estimation error results}

The MBEC simulation uses a change in the PLA setting to correspond to a change in the thrust set point. A PLA step command is used to investigate the controller performance and the matching of the estimated (dashed line) and "true" thrust (solid line). Results for both the takeoff and cruise operating conditions are shown in Fig. 5. The cruise performance is shown on the left given a positive $10^{\circ}$ PLA change over five seconds starting at the 15 second mark followed by a negative $10^{\circ}$ PLA change over five seconds initiating at 45 
seconds. Performance deterioration throughout the engine's lifecycle is simulated by using the deterioration parameter of the CMAPSS40k simulation. Results are shown for engine deterioration levels, or "life cycle" points, of new (black), mid (blue), and EoL engine (red). At each of the life cycle points the performance for the cruise thrust estimation is very comparable and the largest absolute percent error between actual and estimated thrust is usually less than $1.5 \%$. The MBEC control architecture is able to provide a tight control and all of the responses lie nearly on top of each other.
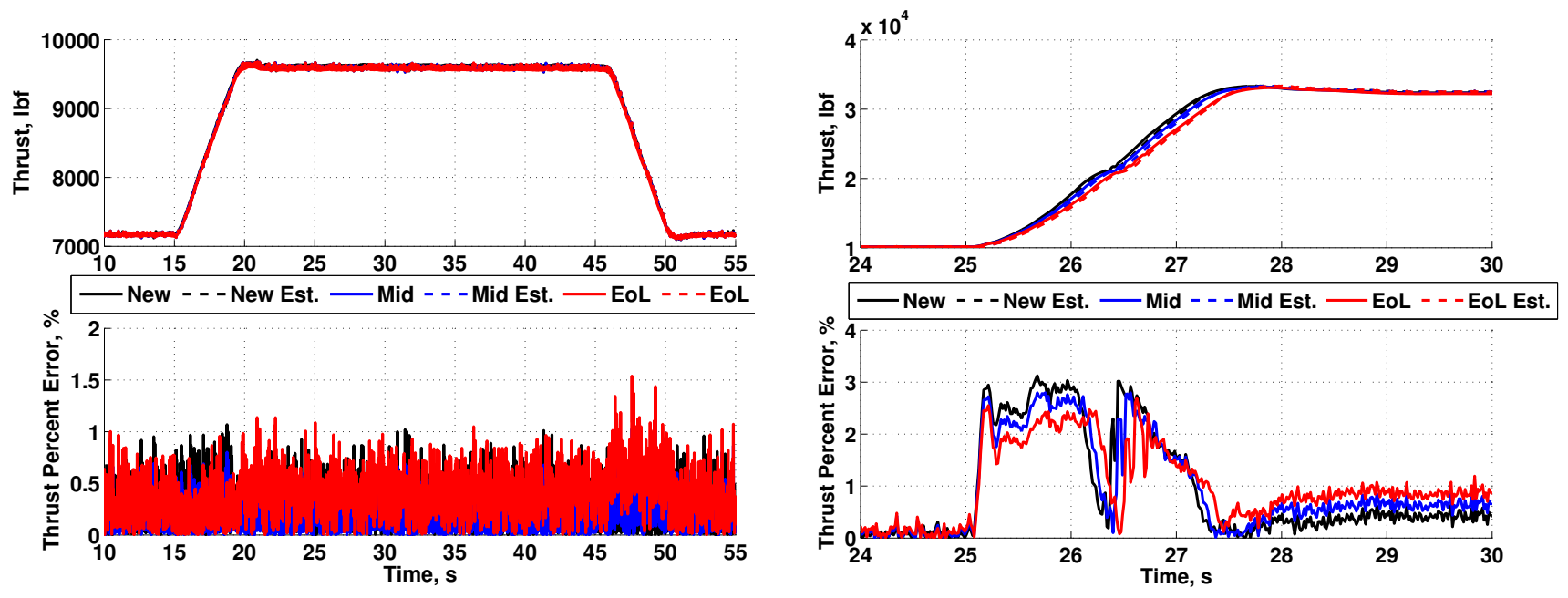

Figure 5. Comparison of the true and estimated thrust of a new, mid, and end of life engine at cruise (left) and takeoff (right) with the respective percent error.

On the right hand side of Fig. 5 the takeoff condition is shown with a PLA change from flight idle to near max power (a positive PLA change of approximately $37^{\circ}$ ) over 0.15 seconds starting at the 25 second mark. This operating condition is at sea level static and represents the FAA federal aviation regulation $33.73,{ }^{17}$ which demands that the engine should be able to go from flight idle to $95 \%$ of full rated takeoff thrust in less than five seconds without causing the engine to stall. The MBEC engine is able to reach $95 \%$ of full rated power from flight idle in less than 5 seconds to meet the FAA requirement. Similar estimation performance to the cruise condition is shown, however the largest estimation error has now increased to approximately $3 \%$ due to the very large transient. Some of this error could possibly be reduced by using more trim points for the Kalman Filter, however the thrust estimation error is relatively small over the engine life cycle and at various operating points.

The stall margin is investigated with the same transient PLA change for takeoff and cruise that was done for the thrust performance investigation. The SM regulator used in the protection logic is designed to limit the SM from falling below 11\%, which accounts for the the non-transient SM stack up shown in Table 1. This mimics the baseline acceleration limiter that is designed to same threshold. Results for both the takeoff and cruise are shown in Fig. 6. The cruise performance is shown on the left given a $10^{\circ}$ PLA change. The stall margin estimation error is typically less than $4 \%$ and has a peak of less than $6 \%$ error. This HPC SM estimation is not as accurate as the thrust estimation, however the OTKF is able to track the general trend during engine degradation.

The takeoff operating point is shown in Fig. 6 on the right, where the transient is again an approximately $37^{\circ}$ PLA change. This large transient command without protection logic would cause the engine to stall. The results show that the HPC limiter is able to prevent the engine from stalling to meet the FAA requirement. The following section will discuss the HPC protection logic in further detail, while the focus in this section is the estimation error. Here again, the steady state error is small and comparable to the cruise condition. However, the transient error can be as large as $20 \%$ due to the very large command. While this is a large percent error, this is still in relation to a percent stall margin, and it will still allow for a reduction in the baseline operability margins used in developing the protection logic.

Another aspect of designing the engine protection logic is guarding against high gas temperatures feeding into the turbine, T40. Typically, this region of the engine is too hot to place a sensor as over temperature 

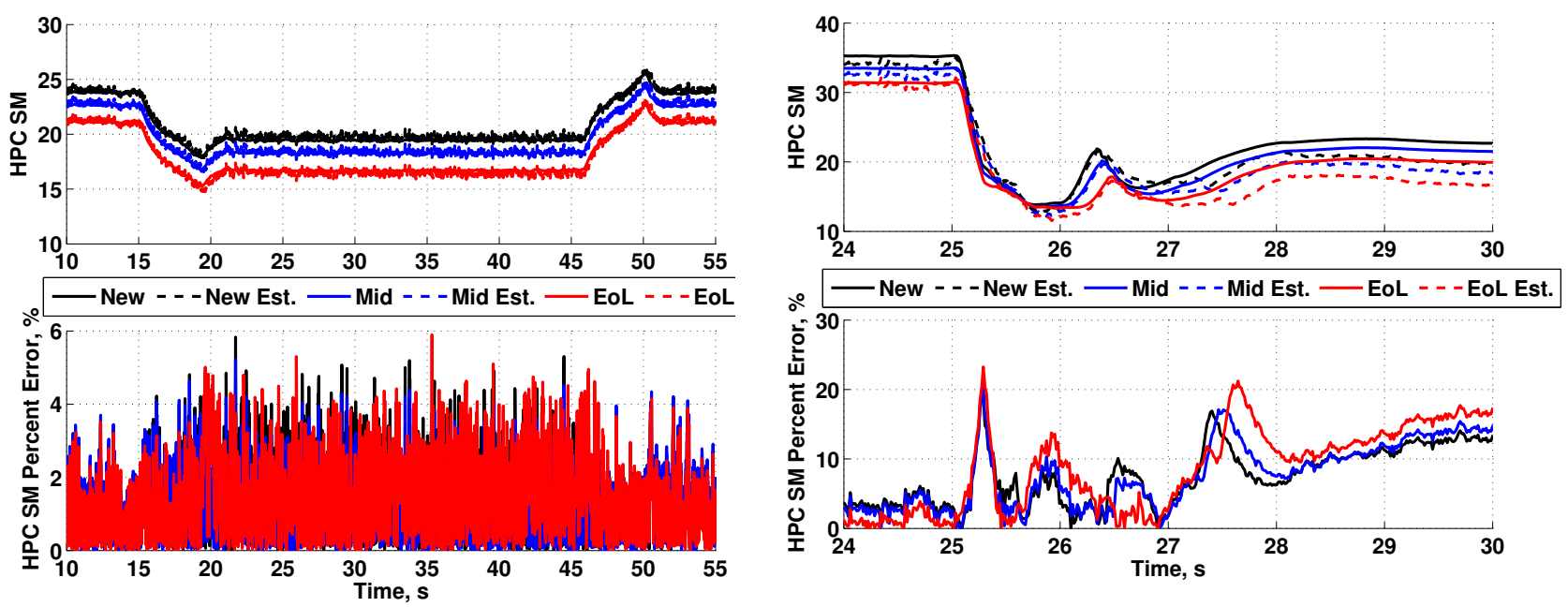

Figure 6. Comparison of the true and estimated stall margin over the engine life cycle at cruise (left) and takeoff (right) with the respective percent error.

protection is implemented by determining the engine operating line to be such that T40 will stay below the maximum allowable temperature throughout the engine life and operating envelope. This approach also introduces conservatism in determining safe steady state operating line. If a good estimate of T40 can be obtained then a temperature regulator can be designed to ensure that maximum temperature limits are not exceeded. The OTKF in the MBEC architecture allows for estimates of this temperature to be taken into account in the control design. The estimates of T40 at both the cruise and takeoff operating condition are shown in Fig. 7. The estimation of T40 is very accurate at both operating conditions and over the engine life cycle, producing only a $1 \%$ error at cruise and $6 \%$ error at takeoff.
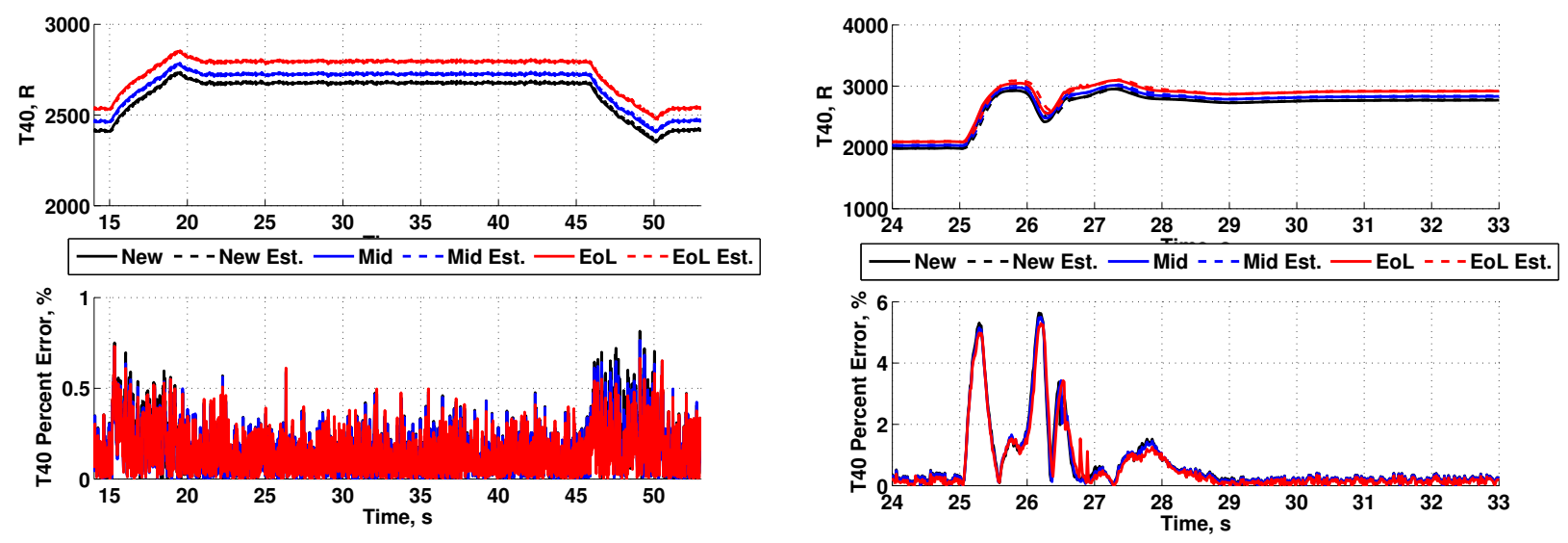

Figure 7. Comparison of the true and estimated T40 over the engine life cycle at cruise (left) and takeoff (right) with the respective percent error. 


\section{Stall margin protection logic results}

This section illustrates a performance comparison between the MBEC protection logic using the estimate of the HPC SM and the baseline CMAPSS40k EPR controller using an acceleration limiter. The transient used for the analysis is for a slightly larger transient than the aforementioned FAA requirement. In this section, the full PLA command range is used to illustrate a case where the protection logic is certain to be required for safe operation. The acceleration limiter is designed to have approximately 11\% HPC SM during a large transient to provide enough margin to safely operate even an EoL engine. The margin is obtained from Table 1 by subtracting the transient from the stall margin stack up. The SM limiter regulator replaces the acceleration limit for the MBEC architecture, where a lower value is sought to illustrate improved thrust response. A SM threshold of only a few percent is possible based on the estimation accuracy shown in the previous section, however this lowering of the limit can have a significant impact on other aspects of the engine operation. It was determined for this study that the SM threshold would be lowered to a value of $8 \%$ to prevent the MBEC design from having a higher max T40 than the baseline. In Fig. 8 and 9 the baseline controller response is shown for a new (dashed black), mid (dashed blue) and EoL engine (dashed red). The MBEC controller response is shown in Fig. 8 and 9 for a new (black), mid (blue) and EoL engine (red). The comparison of the two controllers are obtained by first executing the baseline controller to get an initial steady state value of thrust and a final steady state value after the transient to specify the MBEC thrust command set points.
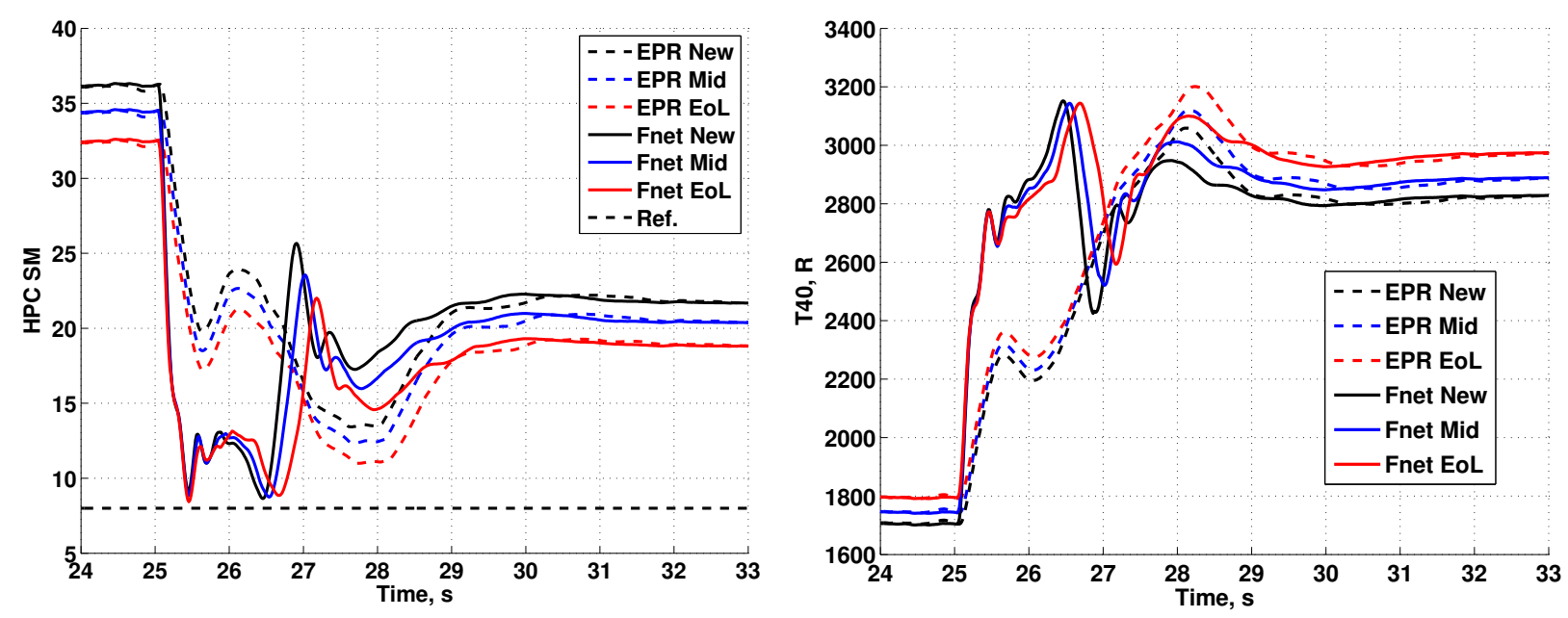

Figure 8. Comparison of the MBEC and baseline controller protection logic over the engine life cycle for the HPC SM (left) and T40 (right).

The estimation of the stall margin shown in Fig. 6 illustrated that the typical deterioration uncertainty in the stall margin stack up can be reduced. For the analysis presented here a SM threshold of $8 \%$ was chosen to provide margin for uncertainty in the estimation and not allow the transient response to significantly exceed the value of T40 for the baseline control architecture. In the results that follow, the estimation error is no longer shown as the approximate percent error of the estimation as was illustrated in the previous section. However, the MBEC controller is still closing the loop on the estimated parameters.

The large transient for this study causes the limiter to engage, which prevents the engine from violating the threshold by limiting the fuel flow. The results shown for the HPC SM in the left plot of Fig. 8 illustrate that both protection logic schemes prevent the engine from surging. However, the MBEC protection logic enables engine operation at a lower level of HPC stall margin as opposed to the conventional core acceleration limit approach, which must apply more conservative logic for an EoL engine. In addition, since the MBEC controller is closed on an accurate estimate of the desired HPC SM parameter, a tighter controller is possible. It is clearly shown in Fig. 8 that the response of the MBEC architecture has less variation during the transient near the limit over the engine life cycle compared to the response of the EPR controller with an acceleration limiter. The right plot of Fig. 8 shows that while the MBEC limiter allows for the HPC SM transient to propagate more freely before the limiter is engaged, the combustor exit temperature peak is approximately 


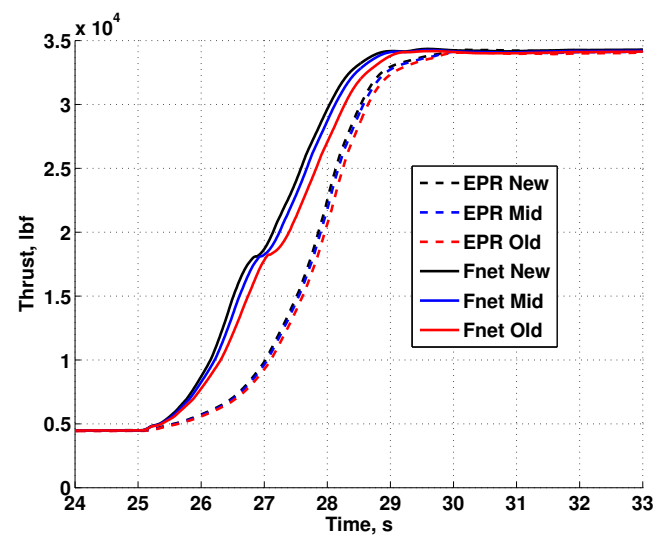

Figure 9. Comparison of the MBEC and baseline controller protection logic over the engine life cycle for the thrust response.

the same as that of the baseline controller.

Since the limiter regulates the fuel flow its design has a large impact on the thrust transient as illustrated in Fig. 9. The MBEC control limiter has a significant response time advantage over the baseline controller using the acceleration limiter. A tight control of the HPC SM is a key potential benefit of the MBEC control design approach. The significance of this, beyond a faster large transient response, would be for the working line of the engine to be allowed to move to a more efficient regime of the operating envelope. This region is typically excluded due to stall margin requirements due to engine life deterioration. If the engine is able to operate more efficiently by the redesign of the working line then the goal of improving the thrust specific fuel consumption can be obtained.

\section{Fan fault and tighter thrust control}

To investigate if the MBEC design could provide a tighter control than the baseline $\mathrm{N}_{\mathrm{f}} / \mathrm{EPR}$ controllers over the engine life cycle, several operating points were investigated. The baseline controller is executed at various deterioration levels and the response of the non-deteriorated engine thrust profile is saved to be used as the thrust command for the MBEC controller design. The general trends from this investigation will be discussed, but the results shown in Fig. 10 are for the previously described cruise operating point and compared to the $\mathrm{N}_{\mathrm{f}}$ baseline controller. The same color scheme for the plotted results are used from the previous section. The MBEC design has less than $1 \%$ error in thrust over the engine life cycle as was shown in Fig. 5. The right plot of Fig. 10 shows that the thrust range for the MBEC design is approximately 60 lbf, while the $\mathrm{N}_{\mathrm{f}}$ control design has a variation of about $90 \mathrm{lbf}$. While the MBEC design here is slightly tighter than the $\mathrm{N}_{\mathrm{f}}$ design, both controllers provide a very tight margin. When comparing other operating points the $\mathrm{N}_{\mathrm{f}}$ design typically had slightly greater thrust variation, but this was not always true for low altitudes. The CMAPSS40k EPR baseline controller always had a smaller thrust variation over the engine life cycle, when compared to the MBEC control design.

The small variation of the thrust over the engine life cycle shown in all of the results, only about $1 \%$, is due to the specific deterioration profile for the CMAPSS40k simulation. The MBEC architecture could potentially provide a tighter thrust control for other engines, where the deterioration is expected to have a greater impact on the thrust output. Previous studies have shown that the deterioration can cause larger thrust variations of up to $3 \% .{ }^{18,19}$ In these cases the MEBC design could provide a significant benefit.

Another area the MEBC control design could provide a benefit is in the case of a fault that would impact the thrust output. A notional fan fault is simulated here, where the fan efficiency and flow capacity is decreased by $3 \%$ at the 25 second mark of a simulation using the cruise operating point profile. The flow capacity drop of $3 \%$ is approximately an order of magnitude larger than a typical decrease in a naturally degraded EoL engine. Here the PLA is held fixed and the transient change is only due to the fan fault. A comparison of the thrust response using the MBEC design to the $\mathrm{N}_{\mathrm{f}}$ baseline controller is shown in Fig. 11. The results show that the fault causes both of the designs to deviate from the commanded set point, but 

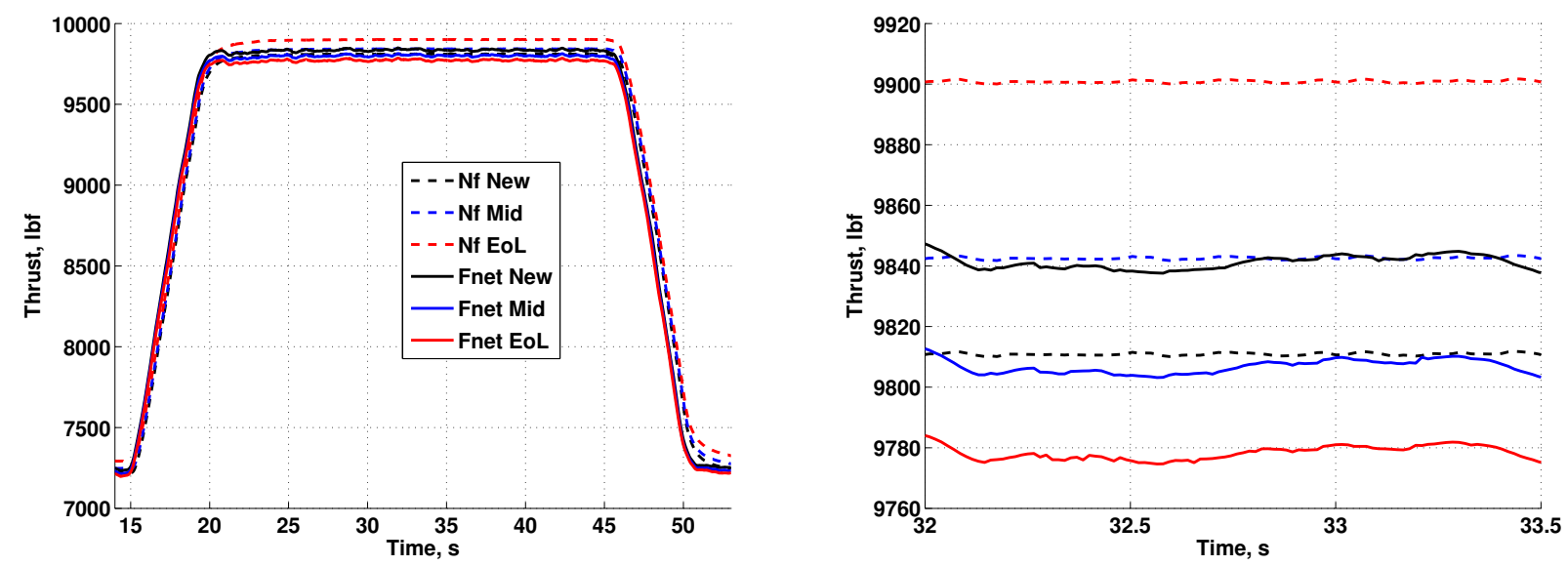

Figure 10. Comparison of the MBEC and $\mathrm{N}_{\mathrm{f}}$ baseline controller to provide a tight control of thrust over the engine life cycle (left) and a zoomed in portion of the thrust response after the initial transient (right).

the MBEC design is impacted to a lesser degree. Note that the MBEC tracks the estimated Fnet, however the on-board model has significant error in estimating Fnet in the pretense of the large fan fault. The use of MBEC to maintain desired performance during faults is an area of ongoing investigation.

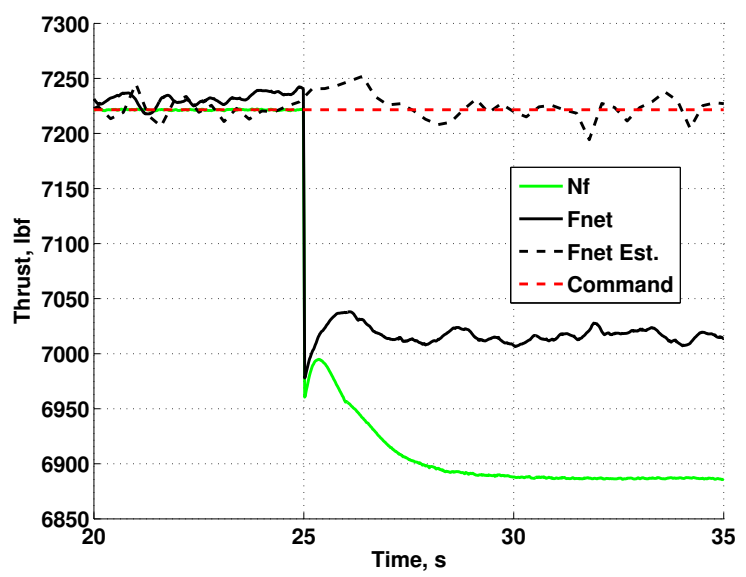

Figure 11. Thrust response comparison of the MBEC control design to $\mathrm{N}_{\mathrm{f}}$ baseline during a fan fault of $3 \%$ reduction in efficiency and flow capacity.

\section{Future Work}

The work presented here illustrated the potential benefit of an MBEC architecture, however to show real efficiency gains a redesign of the engine operating line is required. The MBEC control architecture was shown to open up new areas of the compressor performance map that now can be used to explore more efficient operating conditions. Ongoing work is investigating the efficiency contours of the engine performance maps that can be used to design the new operating line, which will be used to test possible reductions in specific fuel consumption. Since fan faults due to foreign object damage are a relatively common occurrence, the capability to estimate the thrust accurately in the presence of a fan fault needs to be investigated further. Although nothing in this MEBC architecture is adaptive and thus non-deterministic, some means of validating that the estimated values are reasonable will need to be incorporated. 


\section{Conclusions}

The development of a model-based engine control (MBEC) design applied to the Commercial Modular Aero-Propulsion System Simulation 40,000 (CMAPSS40k) turbofan engine simulation and an optimal tuner Kalman Filter (OTKF) estimation routine as the on-board model was shown. The focus was on developing a MBEC design using an OTKF estimation of thrust and high pressure compressor stall margin to replace the baseline turbofan engine feedback control and limiting parameters. The MBEC simulation was shown to provide a tight control bound on thrust over the entire life cycle of the engine. The OTKF provided accurate estimates of the control parameters of interest at cruise and during a large takeoff transient. The most significant result shown is the accurate estimation of the high pressure compressor stall margin. This allowed for the development of a stall margin protection logic that improved the transient response over the baseline control architecture. The MBEC control architecture was also shown to provide a tighter control of thrust in the case of a fan fault.

\section{Acknowledgements}

The authors would like to acknowledge Don Simon for sharing his expertise in the optimal tuner Kalman Filter, which was an enabling technology for this model-based engine control research, and Sanjay Garg for guidance in the MBEC architecture development.

\section{References}

1 "NASA Fact Sheet: Energy, Efficiency and Emissions." Tech. Rep. NASA/NF-2009-08-488-HQ, NASA, 2009.

${ }^{2}$ May, R., Csank, J., Litt, J. S., and Guo, T., "Commercial Modular Aero-Propulsion System Simulation 40K," Tech. Rep. NASA/TM 2010-216810, NASA, 2009.

${ }^{3}$ Connolly, J., Chicatelli, A., and Garg, S., "Model-Based Control of an Aircraft Engine using an Optimal Tuner Approach," 48th AIAA/ASME/SAE/ASEE Joint Propulsion Conference, No. AIAA 2012-4257, 2012.

${ }^{4}$ Garg, S., Kumar, A., Mathews, H. K., Rosenfeld, T., Rybarik, P., and Viassolo, D., "More Intelligent Gas Turbine Engines," Intelligent Control and Health Monitoring, No. TR-AVT-128, chap. 3, NATO Research and Technology Organization, 2009 .

${ }^{5}$ Behbahani, A., Adibhatla, S., and Rauche, C., "Integrated Model-Based Controls and PHM for Improving Turbing Engine Performance, Reliability, and Cost," 45th AIAA/ASME/SAE/ASEE Joint Propulsion Conference, No. AIAA 2009-5534, 2009.

${ }^{6}$ Fuller, J. W., Kumar, A., and Millar, R. C., "Adaptive Model Based Control of Aircraft Propulsion Systems: Status and Outlook for Naval Aviation Applications," ASME Turbo Expo: Power for Land, Sea and Air, No. GT2006-90241, May 8-11 2006.

${ }^{7}$ Lietzau, K. and Kreiner, A., "Model Based Control Concepts for Jet Engines," ASME Turbo Expo: Power for Land, Sea and Air, No. GT2001-0016, 2001.

${ }^{8}$ Brunell, B. J., Viassolo, D. E., and Prasanth, R., "Model Adaptation and Nonlinear Model Predictive Control of an Aircraft Engine," ASME Turbo Expo: Power for Land, Sea and Air, No. GT2004-53780, 2004.

${ }^{9}$ Adibhatla, S. and Gastineau, S., "Tracking Filter Selection and Control Mode Selection for Model Based Control," 30th AIAA/ASME/SAE/ASEE Joint Propulsion Conference, No. AIAA 94-3204, 1994.

${ }^{10}$ Turevskiy, A., Meisner, R., Luppold, R. H., Kern, R. A., and Fuller, J. W., "A Model-Based Controller for Commercial Aero Gas Turbines," ASME Turbo Expo: Power for Land, Sea and Air, No. GT2002 - 30041, 2002.

${ }^{11}$ Henriksson, M. and Ring, D., "Robust Kalman Filter Thrust Estimation in a Turbofan Engine," ASME Turbo Expo: Power for Land, Sea and Air, No. GT2006-91241, 2006.

${ }^{12}$ Ring, D. and Henriksson, M., "Thrust Control for a Turbofan Engine Using Estimation," ASME Turbo Expo: Power for Land, Sea and Air, No. GT2006-91251, 2006.

${ }^{13} \mathrm{Mu}$, J. and Rees, D., "Nonlinear Model Predictive Control for Gas Turbine Engines," ASME Turbo Expo: Power for Land, Sea and Air, No. GT2004-53146, 2004.

${ }^{14}$ Simon, D. L. and Garg, S., "Optimal Tuner Selection for Kalman Filter-Based Aircraft Engine Performance Estimation," Tech. Rep. NASA/TM 2010-216076, NASA, 2010.

${ }^{15}$ Walsh, P. P. and Fletcher, P., Gas Turbine Performance, ASME Press, Blackwell Publishing, NJ, 2nd ed., 2004.

${ }^{16}$ Csank, J., Ryan, M., Litt, J. S., and Guo, T., "Control Design for a Generic Commercial Aircraft Engine," Tech. rep., NASA/TM 2010-216811, 2010.

${ }^{17}$ FAA, "FAR: Title 14 Part 33.73 Power or thrust response," .

${ }^{18}$ Litt, J., Showers, T., and Garg, S., "A Retro-Fit Control Architacture to Maintain Engine Performance," Tech. rep., NASA/TM 2007-214977, 2007.

${ }^{19}$ Brown, H. and Desai, P., "Methods and Apparatus for Estimating Engine Thrust," United States Patent Application Publication - US 2007/0260424 A1, 2007. 
NASA/TM-2013-216551

ISt

Model-Based Control of a Nonlinear Aircraft Engine Simulation Using an Optimal Tuner Kalman Filter Approach

Joseph W. Connolly and Jeffrey T. Csank

Glenn Research Center, Cleveland, Ohio

Amy K. Chicatelli

Vantage Partner LLC, Brook Park, Ohio

Jacob Kilver

Ohio State University, Columbus, Ohio 


\section{NASA STI Program . . . in Profile}

Since its founding, NASA has been dedicated to the advancement of aeronautics and space science. The NASA Scientific and Technical Information (STI) program plays a key part in helping NASA maintain this important role.

The NASA STI Program operates under the auspices of the Agency Chief Information Officer. It collects, organizes, provides for archiving, and disseminates NASA's STI. The NASA STI program provides access to the NASA Aeronautics and Space Database and its public interface, the NASA Technical Reports Server, thus providing one of the largest collections of aeronautical and space science STI in the world. Results are published in both non-NASA channels and by NASA in the NASA STI Report Series, which includes the following report types:

- TECHNICAL PUBLICATION. Reports of completed research or a major significant phase of research that present the results of NASA programs and include extensive data or theoretical analysis. Includes compilations of significant scientific and technical data and information deemed to be of continuing reference value. NASA counterpart of peer-reviewed formal professional papers but has less stringent limitations on manuscript length and extent of graphic presentations.

- TECHNICAL MEMORANDUM. Scientific and technical findings that are preliminary or of specialized interest, e.g., quick release reports, working papers, and bibliographies that contain minimal annotation. Does not contain extensive analysis.

- CONTRACTOR REPORT. Scientific and technical findings by NASA-sponsored contractors and grantees.
- CONFERENCE PUBLICATION. Collected papers from scientific and technical conferences, symposia, seminars, or other meetings sponsored or cosponsored by NASA.

- SPECIAL PUBLICATION. Scientific, technical, or historical information from NASA programs, projects, and missions, often concerned with subjects having substantial public interest.

- TECHNICAL TRANSLATION. Englishlanguage translations of foreign scientific and technical material pertinent to NASA's mission.

Specialized services also include creating custom thesauri, building customized databases, organizing and publishing research results.

For more information about the NASA STI program, see the following:

- Access the NASA STI program home page at http://www.sti.nasa.gov

- E-mail your question to help@sti.nasa.gov

- Fax your question to the NASA STI Information Desk at 443-757-5803

- Phone the NASA STI Information Desk at 443-757-5802

- Write to: STI Information Desk NASA Center for AeroSpace Information 7115 Standard Drive Hanover, MD 21076-1320 
NASA/TM-2013-216551

rate

Model-Based Control of a Nonlinear Aircraft Engine Simulation Using an Optimal Tuner Kalman Filter Approach

Joseph W. Connolly and Jeffrey T. Csank

Glenn Research Center, Cleveland, Ohio

Amy K. Chicatelli

Vantage Partner LLC, Brook Park, Ohio

Jacob Kilver

Ohio State University, Columbus, Ohio

Prepared for the

49th Joint Propulsion Conference and Exhibit

cosponsored by AIAA, ASME, SAE, and ASEE

San Jose, California, July 14-17, 2013

National Aeronautics and

Space Administration

Glenn Research Center

Cleveland, Ohio 44135 


\section{Acknowledgments}

The authors would like to acknowledge Don Simon for sharing his expertise in the optimal tuner Kalman Filter, which was an enabling technology for this model-based engine control research, and Sanjay Garg for guidance in the model-based engine control (MBEC) architecture development.

This report is a formal draft or working paper, intended to solicit comments and ideas from a technical peer group.

This report contains preliminary findings, subject to revision as analysis proceeds.

Trade names and trademarks are used in this report for identification only. Their usage does not constitute an official endorsement, either expressed or implied, by the National Aeronautics and Space Administration.

Level of Review: This material has been technically reviewed by technical management.

Available from

NASA Center for Aerospace Information 7115 Standard Drive

Hanover, MD 21076-1320
National Technical Information Service 5301 Shawnee Road Alexandria, VA 22312 


\title{
Model-Based Control of a Nonlinear Aircraft Engine Simulation Using an Optimal Tuner Kalman Filter Approach
}

\author{
Joseph W. Connolly and Jeffrey T. Csank \\ National Aeronautics and Space Administration \\ Glenn Research Center \\ Cleveland, Ohio 44135 \\ Amy K. Chicatelli \\ Vantage Partner LLC \\ Brook Park, Ohio 44142 \\ Jacob Kilver \\ Ohio State University \\ Columbus, Ohio 43210
}

\begin{abstract}
This paper covers the development of a model-based engine control (MBEC) methodology featuring a self tuning on-board model applied to an aircraft turbofan engine simulation. Here, the Commercial Modular Aero-Propulsion System Simulation 40,000 (CMAPSS40k) serves as the MBEC application engine. CMAPSS40k is capable of modeling realistic engine performance, allowing for a verification of the MBEC over a wide range of operating points. The on-board model is a piece-wise linear model derived from CMAPSS40k and updated using an optimal tuner Kalman Filter (OTKF) estimation routine, which enables the on-board model to self-tune to account for engine performance variations. The focus here is on developing a methodology for MBEC with direct control of estimated parameters of interest such as thrust and stall margins. Investigations using the MBEC to provide a stall margin limit for the controller protection logic are presented that could provide benefits over a simple acceleration schedule that is currently used in traditional engine control architectures.
\end{abstract}

\section{Nomenclature}

\begin{tabular}{|c|c|c|c|}
\hline CMAPSS40k & $\begin{array}{l}\text { Commercial modular aero-propulsion } \\
\text { system simulation } 40,000\end{array}$ & Ps3 & $\begin{array}{l}\text { High pressure compressor static } \\
\text { discharge pressure }\end{array}$ \\
\hline EoL & End of life & $R U$ & Ratio unit $\left(\frac{W_{f}}{\mathrm{Ps}_{3}}\right)$ decceleration limiter \\
\hline EPR & Engine pressure ratio & $\mathrm{SM}$ & Stall margin \\
\hline $\mathrm{F}_{\mathrm{NET}}$ & Engine net thrust & $\mathrm{T} 3$ & High pressure compressor discharge \\
\hline FAA & Federal aviation administration & & temperature \\
\hline HPC & High pressure compressor & $\mathrm{T} 50$ & Low pressure turbine exit temperature \\
\hline MBEC & Model based engine control & $\mathrm{T} 40$ & Combustor exit temperature \\
\hline $\mathrm{N}_{\mathrm{c}}$ & Core rotational speed & VBV & Variable bleed valve \\
\hline $\mathrm{N}_{\mathrm{f}}$ & Fan rotational speed & VSV & Variable stator vane \\
\hline OTKF & Optimal tuner Kalman Filter & $W_{f}$ & Fuel flow \\
\hline P50 & Low pressure turbine exit pressure & $e$ & Error \\
\hline PI & Proportional integral controller & & \\
\hline PLA & Power lever angle & & \\
\hline
\end{tabular}




\section{Introduction}

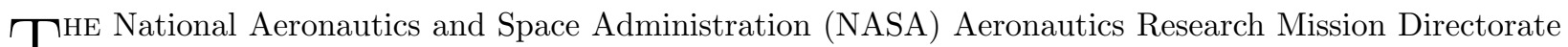
aims to develop technologies to improve the safety and fuel efficiency of commercial aircraft. Conservation of fuel in transportation systems has been identified as a national goal to reduce harmful emissions and is recognized as a responsibility that requires government involvement in order to be achieved. NASA has documented that reduction in air pollution and operational costs can be accomplished by creating technologies that reduce the following: drag, engine-specific fuel consumption and aircraft weight. ${ }^{1}$ Modelbased engine control (MBEC) is being developed as one of the advanced engine control system methodologies to improve turbofan engine efficiency. In addition, MBEC has potential to provide performance enhancement to transient turbofan engine responses.

In current engine control architectures, the typical design approach is to regulate a measurable variable such as fan shaft speed (Nf) or engine pressure ratio (EPR), which is correlated with thrust. This is done since engine thrust is not a measurable parameter from typical on-board engine sensors. Additionally, limits on allowable fuel flow are imposed based on a conservative approach to maintain adequate stall margin (SM) for safe operation of the engine throughout its life. This approach results in less efficient engine operation and leads to variations in the engine throttle to thrust response with engine deterioration. As an engine deteriorates with usage, the same throttle setting results in slightly different thrust because the relationship of the regulated variable (Nf or EPR) to thrust changes with engine aging.

MBEC will allow operation with less conservative operability margins, since operability margins discussed in this paper are currently designed to an end of life (EoL) engine, whereas an on-board model can provide a more accurate margin for the actual condition of the engine. The reduction in the operability margins for newer engines through the use of direct stall margin estimation protection logic can increase fuel efficiency. A stall margin limiter can be developed to ensure that a lower stall margin threshold can be used for developing a new operating line while maintaining safe operation during transient changes. By making modifications to the operating line, the goal of obtaining efficiency gains can be realized. The longer term pay-off of this research is to have a personalized control for each specific engine, which adapts to the actual condition of the engine to not only maintain more efficient operation throughout its lifetime, but also increase its useful operating life.

A MBEC architecture is comprised of three main components; first an engine or "truth" model, second an on-board model designed to provide real-time estimates of desired unmeasured parameters, and last a controller with limit protection logic. For the simulation study presented in this paper, the Commercial Modular Aero-Propulsion System Simulation 40,000 (CMAPSS40k) ${ }^{2}$ will serve as the engine that MBEC is applied to, an optimal tuner Kalman Filter (OTKF) will serve as the on-board model providing estimates of thrust and stall margin, and finally a thrust controller with stall margin protection is developed.

This paper builds upon previous work done by the authors using a linear analysis based on a single operating condition at cruise. ${ }^{3}$ The focus in this paper is on the development of a MBEC controller capable of being used throughout the flight envelope and during large transients. The following sections of this paper will discuss a traditional engine control architecture, the MBEC architecture, application of MBEC to CMAPSS40k results for the closed-loop MBEC thrust control with stall margin protection logic, comparisons of a baseline control to MBEC control, future work, and conclusions.

\section{Traditional Control Architecture}

A traditional control architecture for a turbofan engine equipped with a full authority digital engine control is shown in Fig. 1. Turbofan engine controllers are designed to regulate a measurable variable such as $\mathrm{N}_{\mathrm{f}}$ or EPR, which is correlated with thrust. The main interface between the pilot and the control system is the power lever angle (PLA) or throttle, which is used by the controller to set a required $\mathrm{N}_{\mathrm{f}}$ or EPR command. Traditional control design is restricted to these parameters due to the sensors and actuators that are implemented in practice. The measured $\mathrm{N}_{\mathrm{f}}$ or EPR is subtracted from the command set point to create an error signal that goes to the controller to determine a fuel flow $\left(W_{f}\right)$. Protection logic limits the commanded fuel flow to provide safe operation of the engine. Finally, the fuel flow signal is sent to the fuel metering valve. As mentioned previously, the traditional approach can result in less efficient engine operation due to engine-to-engine variations in the throttle to thrust response due to the operability margins being designed for an end-of-life engine, which are more conservative.

For safety and operability, protection logic is used to regulate excessive transients and operating conditions 


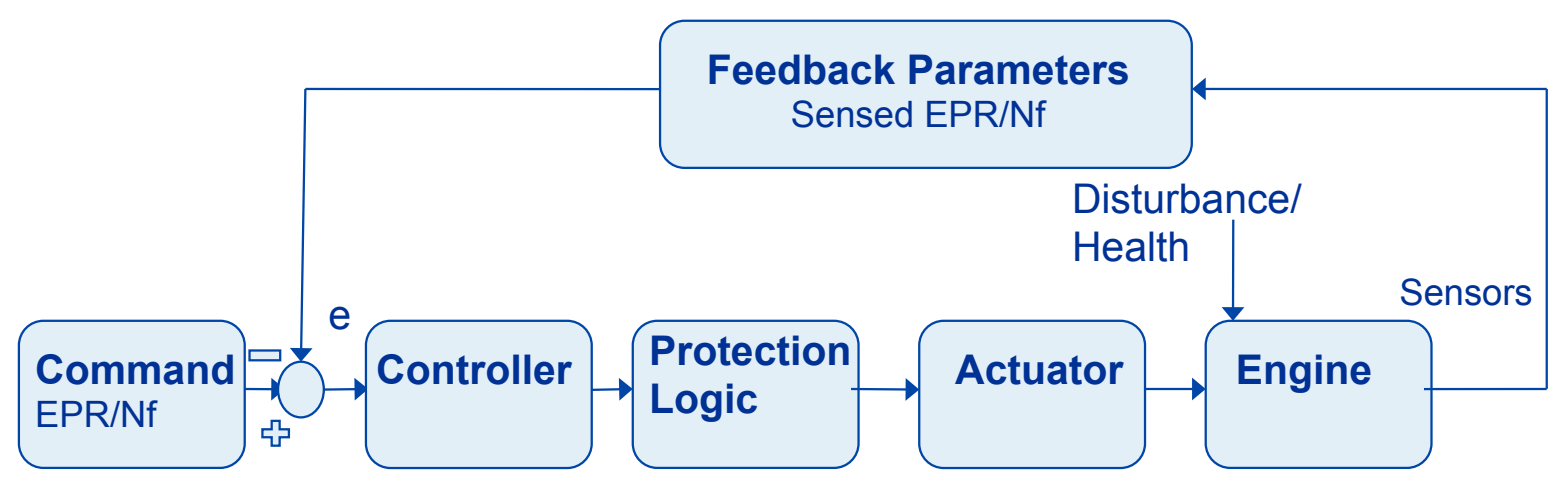

Figure 1. Traditional full authority digital controller diagram.

that could lead to stall or other engine failures, shown in Fig. 2. This is done by monitoring sensed parameters for engine shafts' acceleration, combustor pressure, maximum shaft speeds, and the ratio of $W_{f}$ to compressor discharge static pressure. There is a selection process using a min/max approach to determine the final $W_{f}$ signal that is provided to the fuel metering valve. While all of these limiters are used in traditional aircraft engine control logic, the primary interest in this study is high pressure compressor (HPC) stall margin, and therefore much of the rest of the paper will be focused on the estimation and control of this parameter during engine transients.

\section{Model-Based Engine Control Architecture}

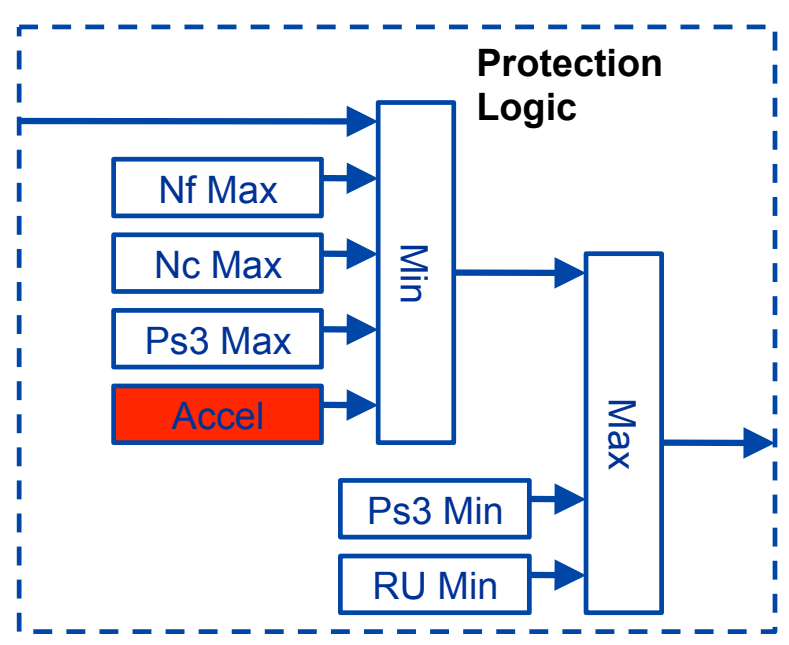

Figure 2. Protection logic limiters that limit the fuel flow based on prescribed operability margins.
In the aircraft engine research community, MBEC is widely recognized as a means to provide the necessary improved efficiency to reduce enginespecific fuel consumption. ${ }^{4-7}$ Although MBEC research has been ongoing for many years by organizations such as General Electric, ${ }^{8,9}$ Pratt and Whitney ${ }^{10}$ and others, ${ }^{11-13}$ one of the stumbling blocks has been the accuracy of the on-board model as the engine degrades with usage. Typically, engine degradation through aging is captured in engine models through health parameters, which are variables such as efficiency and flow capacity that represent performance deterioration within each major rotating component of the engine. The challenge comes about because typically the number of sensors available to update the on-board model to reflect the effects of engine performance deterioration, is less than the number of unknown health parameters. In other MBEC research done to date, a subset of these health parameters equal to the number of available sensors, referred to as tuning parameters, is used to update the on-board model. Although this approach results in good model estimates of the measured variables, it does not necessarily guarantee a good estimate of the unmeasured variables such as thrust and stall margin.

A general schematic of the MBEC architecture applied in this study is shown in Fig. 3. This architecture contains an engine simulation, an on-board model with an associated tracking filter for estimating unmeasured parameters, and a controller with protection logic. In MBEC, the $\mathrm{N}_{\mathrm{f}}$ or EPR regulation is replaced by regulation of net thrust (Fnet), and the acceleration protection limit shown in red of Fig. 2 is replaced by a direct HPC SM limiter. The thrust and limit controllers are designed as simple proportional integral (PI) controllers, which is consistent with PI control design strategies applied in traditional control architectures. The protection logic uses a min/max logic to provide an appropriate fuel flow command to the actuator. Within the on-board self-tuning engine model, an OTKF estimation routine is used to tune the on-board 


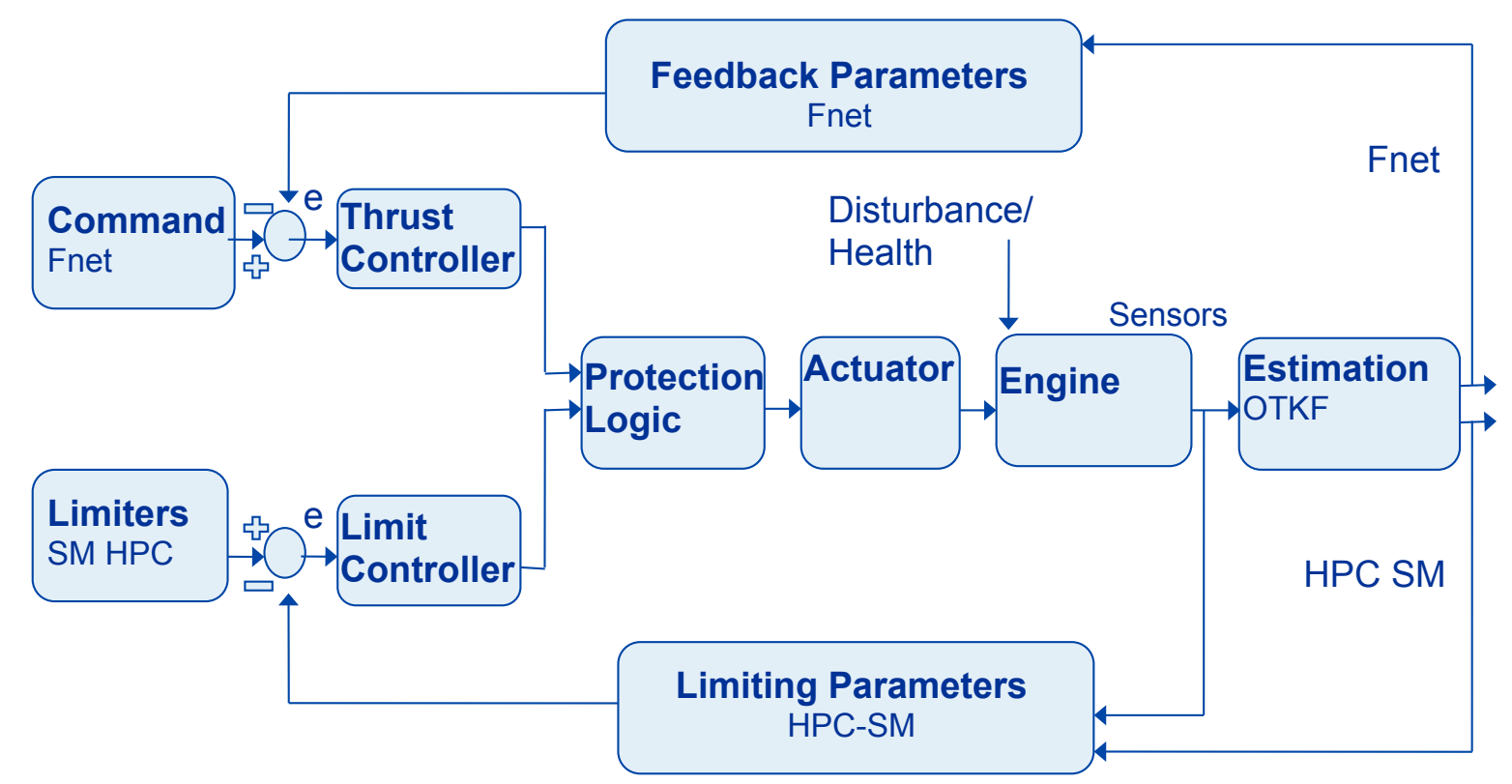

Figure 3. MBEC engine control model architecture.

model to the current engine condition. The OTKF is based on work performed by Simon, ${ }^{14}$ including its follow-on algorithm development. For the MBEC design, the control feedback parameters are not directly sensed, but are instead estimated by the OTKF. The following subsections will provide details about the on-board engine model and OTKF, the controller, and protection logic.

\section{Optimal tuner Kalman Filter}

Through research done under NASA's Aviation Safety Program, the OTKF approach has been developed to select tuning parameters that minimize the Kalman Filter mean squared estimation error in the unmeasured variables of interest. ${ }^{14}$ Developing a MBEC methodology around this OTKF approach provides the capability to overcome the inadequacies of past approaches and makes it practical to achieve the potential benefits of MBEC. Given the updated tuning parameters, a new control methodology can be implemented for directly controlling on thrust instead of $\mathrm{N}_{\mathrm{f}}$ or EPR. The OTKF uses a traditional set of engine sensors to provide estimates of non-sensed parameters such as stall margin and thrust.

The OTKF approach provides an optimal

Table 1. Stall margin stack up used for operability limits is designing limiters and operating schedules.

\begin{tabular}{|l|c|}
\hline Debit Due To & $\%$ \\
\hline Engine to Engine Variation & $4.0 \%$ \\
\hline Reynolds Number Effects & $1.0 \%$ \\
\hline Working Line Deterioration & $2.0 \%$ \\
\hline Stall Line Deterioration & $4.0 \%$ \\
\hline Transient Allowance & $12.0 \%$ \\
\hline Surge Margin Required & $\mathbf{2 3} \%$ \\
\hline
\end{tabular}

Kalman Filter that is calculated based on a global optimization routine for the estimated parameters of interest at operating points spanning the flight envelope. This optimization process can take on the order of tens of minutes, but only needs to be done once during the design phase of the OTKF.

\section{MBEC development}

Given the engine and on-board engine estimation elements developed, a thrust controller and stall margin protection logic can be developed over the full flight envelope to obtain the overall MBEC architecture. In Fig. 3 the MBEC simulation block diagram is illustrated. The thrust controller is directly closed around the estimated thrust and stall margin information is provided to the controller protection logic allowing for a reduction in the conservative margins providing improved efficiency of the turbofan engine. 
The reduction in the operability margins for newer engines through the use of direct stall margin estimation protection logic has the potential to increase fuel efficiency. The focus for this study is on using MBEC to improve the protection logic for the HPC SM as it plays an important role in designing the engine operating line. Table 1 shows a typical stack up of the effects considered in establishing the amount of compressor stall margin that the controller should be designed to maintain. ${ }^{15}$ Given this SM stack up a baseline engine control will have a steady state operating condition designed to have approximately a $23 \%$ margin. Several of the SM effects, or debits, are due to engine-to-engine variation or deterioration. Through MBEC, a stall margin limiter can be developed to ensure that a lower stall margin threshold can be used for developing a new operating line while maintaining safe operation during transient changes. The potential new operating line development is illustrated in Fig. 4 for the HPC map. The red line represents the stall line, the cyan line a notional baseline operating line, and the magenta a potential operating line with reduced stall margin. If perfect estimation of engine deterioration could be obtained, then the SM from Table 1 shows that only a $13 \%$ margin would be required to account for the Reynolds number and transient operation. The operating line redesign space is then illustrated in Fig. 4 between the two plotted operating lines. By making modifications to the operating line, the goal of obtaining efficiency gains can be realized through the potential higher efficiency closer to the stall line.

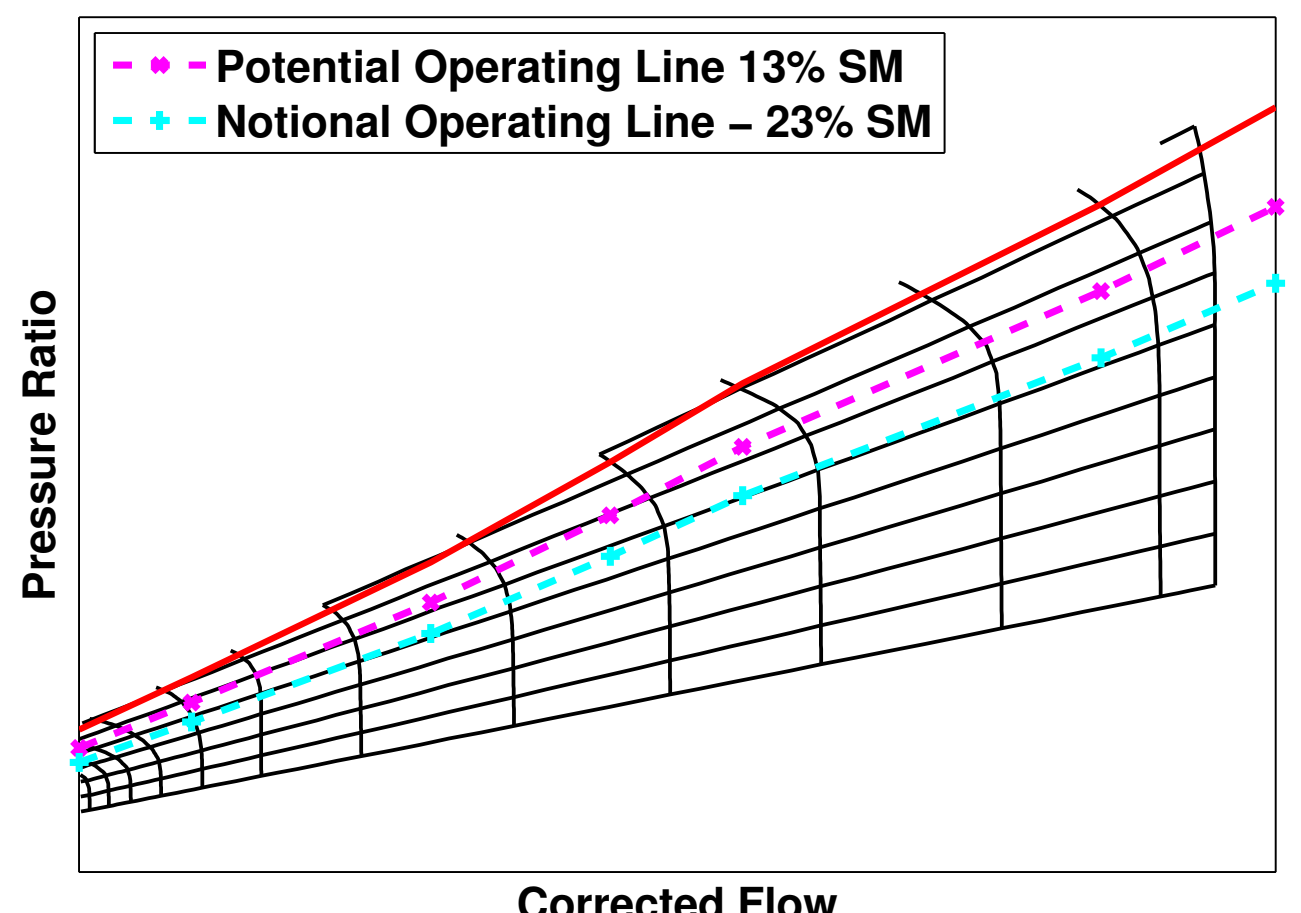

Figure 4. HPC generic compressor map.

The MBEC architecture accepts changes in PLA and converts them to changes in the thrust set point. The thrust controller then uses the error signal to send the fuel flow command to the fuel metering valve actuator. The engine responds to the controller commands and health condition disturbances, and outputs the typical sensed parameters to the OTKF and the controller protection logic. The OTKF then provides an estimate of thrust and stall margin. The overall MBEC architecture is the same as the linear point design MBEC model developed previously, with the primary difference being the piecewise linear scheduling of control gains that allow for operation throughout the operating envelope. ${ }^{3}$ The MBEC controllers mimics the typical PI design for the baseline controller and protection logic to provide a fair comparison between the two methodologies. 


\section{Application of MBEC to CMAPSS40k simulation}

In this study, the CMAPSS40k simulation is used to represent the engine. The CMAPSS40k simulation is a 40,000 lbf class turbofan engine simulation that is specifically designed for the development and testing of control algorithms. The simulation provides realistic transient engine responses and is capable of executing faster than real time. Baseline controllers using EPR and $\mathrm{N}_{\mathrm{f}}$ are provided in CMAPSS40k, along with protection logic similar to that shown in Fig. 2. For the CMAPSS40k simulation the controllers and limiters are designed as a PI control with integrator windup protection. ${ }^{16}$ CMAPSS40k, in addition to controlling the fuel flow schedules the variable stator vane (VSV), and variable bleed valve (VBV).

The model contains a typical suite of sensors for turbofan engine control architectures, which includes:

1. $\mathrm{N}_{\mathrm{c}}$, core speed

2. $\mathrm{N}_{\mathrm{f}}$, fan speed

3. Ps3, high pressure compressor discharge static pressure

4. T3, high pressure compressor discharge temperature

5. T50, low pressure turbine exit temperature

6. P50, low pressure turbine exit pressure

The CMAPSS40k simulation contains a fleet average profile of engine deterioration versus number of flight cycles. By changing the health parameters based on the percent deterioration of the engine, various stages of the engine life cycle can be simulated. To account for deterioration, the efficiency and flow capacity are modified in each of the following engine components: fan, low pressure compressor, high pressure compressor, high pressure turbine, and low pressure turbine.

For the optimal tuner estimation the six control sensors listed above are used. A total of ten health parameters and six sensors represents an underdetermined estimation problem thus illustrating the need for the OTKF approach. The on-board model is a piecewise linear time-invariant state space system developed from CMAPSS40k at an altitude from 0 to 40,000 ft in steps of 20,000 ft, Mach number from 0 to 0.8 in steps of 0.2 , and corrected fan speed from 1200 to $4200 \mathrm{rpm}$ in steps of $400 \mathrm{rpm}$. The piecewise linear model is used to establish the Kalman Filter estimation updates based on sensor inputs. The state vector for the state space model consists of fan and core speeds, and the control input is the fuel flow, VSV, and VBV. The estimated parameters for this study are the values of thrust, HPC stall margin, and combustor exit temperature, T40.

\section{Results}

The simulation results demonstrate the MBEC architecture using a thrust controller and stall margin protection logic at representative cruise and takeoff operating conditions. The cruise condition is for 30,000 $\mathrm{ft}$ altitude, Mach 0.7, and PLA of $60^{\circ}$, while the takeoff condition simulates a transient of going from idle to full power at sea level static conditions. The results shown will first focus on the MBEC controller and the estimation errors obtained, then illustrate the stall margin protection logic compared to the baseline $\mathrm{N}_{\mathrm{f}} / \mathrm{EPR}$ controller and acceleration limiter, and finally look at potential benefits of the MBEC architecture during a fan fault. As mentioned earlier, the major benefit of MBEC is in being able to operate at steady state with a reduced stall margin, which requires redesign of the steady state operating line. This aspect is not addressed in the current work. The focus of the current work is to investigate the feasibility of MBEC to provide safe operation throughout the operating envelope with comparable performance to the baseline control.

\section{MBEC controller and estimation error results}

The MBEC simulation uses a change in the PLA setting to correspond to a change in the thrust set point. A PLA step command is used to investigate the controller performance and the matching of the estimated (dashed line) and "true" thrust (solid line). Results for both the takeoff and cruise operating conditions are shown in Fig. 5. The cruise performance is shown on the left given a positive $10^{\circ}$ PLA change over five seconds starting at the 15 second mark followed by a negative $10^{\circ}$ PLA change over five seconds initiating at 45 
seconds. Performance deterioration throughout the engine's lifecycle is simulated by using the deterioration parameter of the CMAPSS40k simulation. Results are shown for engine deterioration levels, or "life cycle" points, of new (black), mid (blue), and EoL engine (red). At each of the life cycle points the performance for the cruise thrust estimation is very comparable and the largest absolute percent error between actual and estimated thrust is usually less than $1.5 \%$. The MBEC control architecture is able to provide a tight control and all of the responses lie nearly on top of each other.
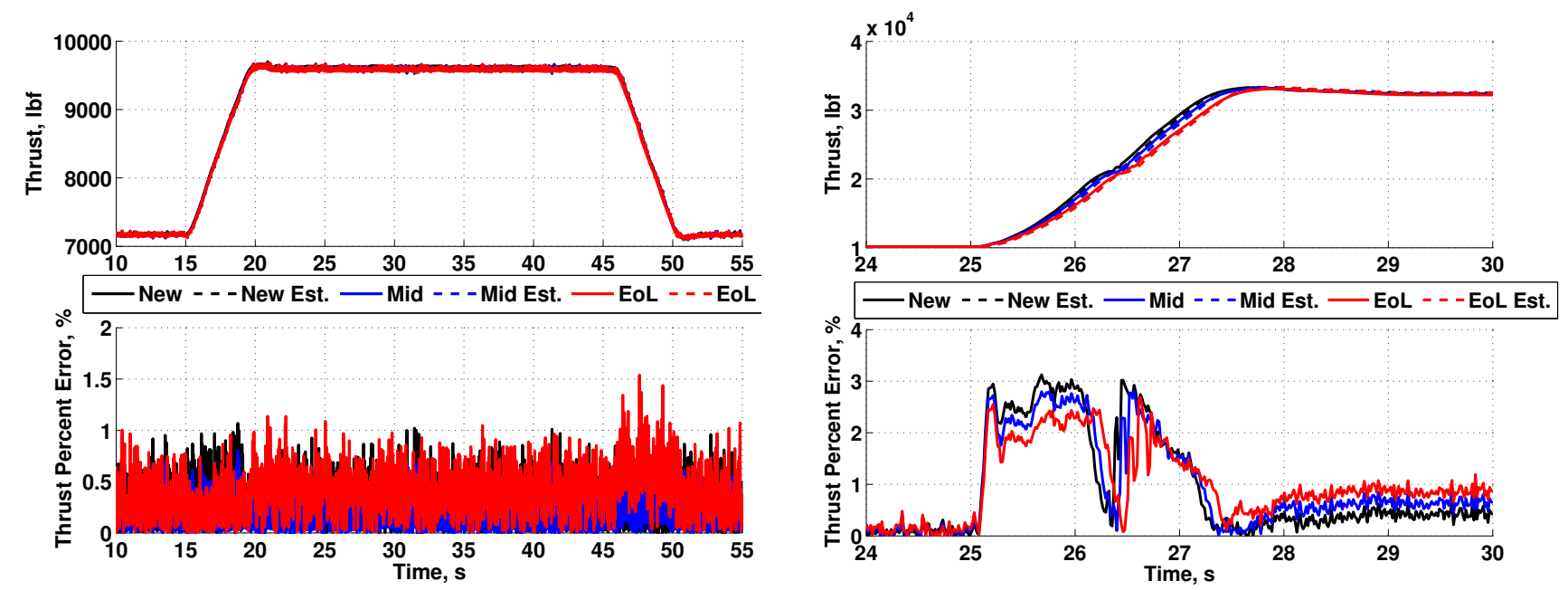

Figure 5. Comparison of the true and estimated thrust of a new, mid, and end of life engine at cruise (left) and takeoff (right) with the respective percent error.

On the right hand side of Fig. 5 the takeoff condition is shown with a PLA change from flight idle to near max power (a positive PLA change of approximately $37^{\circ}$ ) over 0.15 seconds starting at the 25 second mark. This operating condition is at sea level static and represents the FAA federal aviation regulation $33.73,{ }^{17}$ which demands that the engine should be able to go from flight idle to $95 \%$ of full rated takeoff thrust in less than five seconds without causing the engine to stall. The MBEC engine is able to reach $95 \%$ of full rated power from flight idle in less than 5 seconds to meet the FAA requirement. Similar estimation performance to the cruise condition is shown, however the largest estimation error has now increased to approximately $3 \%$ due to the very large transient. Some of this error could possibly be reduced by using more trim points for the Kalman Filter, however the thrust estimation error is relatively small over the engine life cycle and at various operating points.

The stall margin is investigated with the same transient PLA change for takeoff and cruise that was done for the thrust performance investigation. The SM regulator used in the protection logic is designed to limit the SM from falling below 11\%, which accounts for the the non-transient SM stack up shown in Table 1. This mimics the baseline acceleration limiter that is designed to same threshold. Results for both the takeoff and cruise are shown in Fig. 6. The cruise performance is shown on the left given a $10^{\circ}$ PLA change. The stall margin estimation error is typically less than $4 \%$ and has a peak of less than $6 \%$ error. This HPC SM estimation is not as accurate as the thrust estimation, however the OTKF is able to track the general trend during engine degradation.

The takeoff operating point is shown in Fig. 6 on the right, where the transient is again an approximately $37^{\circ}$ PLA change. This large transient command without protection logic would cause the engine to stall. The results show that the HPC limiter is able to prevent the engine from stalling to meet the FAA requirement. The following section will discuss the HPC protection logic in further detail, while the focus in this section is the estimation error. Here again, the steady state error is small and comparable to the cruise condition. However, the transient error can be as large as $20 \%$ due to the very large command. While this is a large percent error, this is still in relation to a percent stall margin, and it will still allow for a reduction in the baseline operability margins used in developing the protection logic.

Another aspect of designing the engine protection logic is guarding against high gas temperatures feeding into the turbine, T40. Typically, this region of the engine is too hot to place a sensor as over temperature 

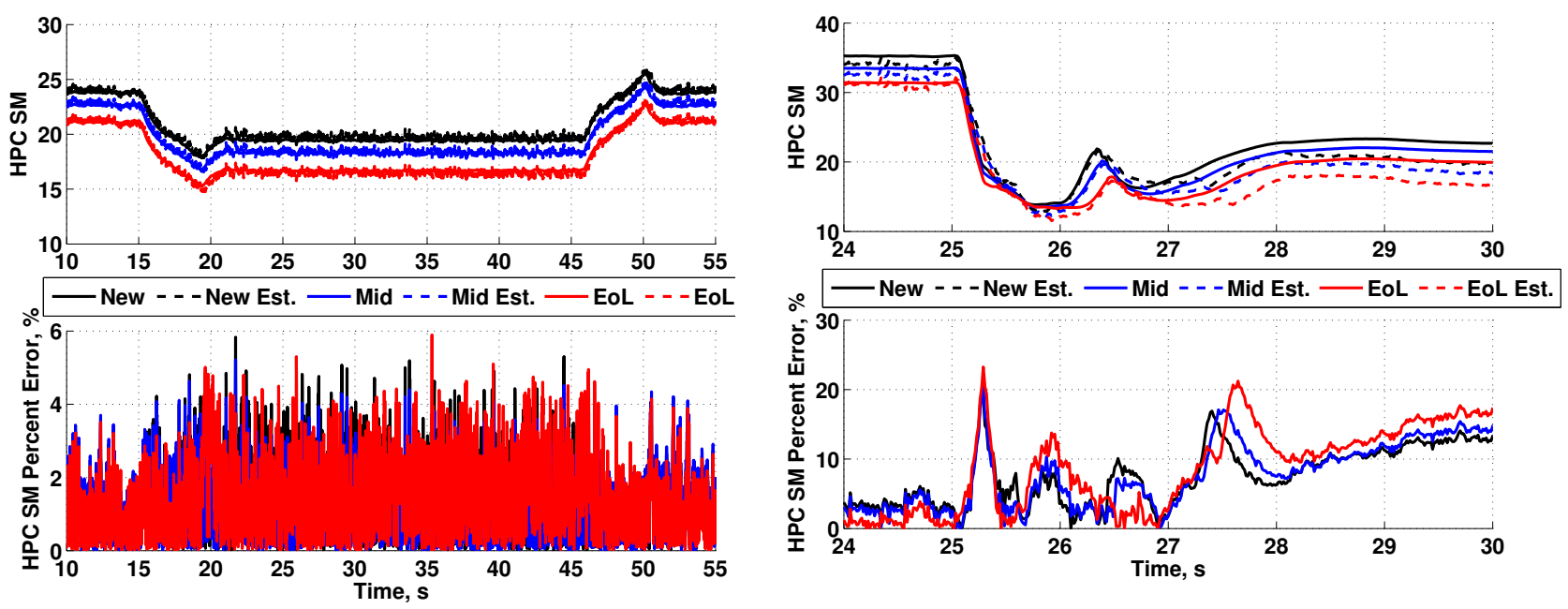

Figure 6. Comparison of the true and estimated stall margin over the engine life cycle at cruise (left) and takeoff (right) with the respective percent error.

protection is implemented by determining the engine operating line to be such that T40 will stay below the maximum allowable temperature throughout the engine life and operating envelope. This approach also introduces conservatism in determining safe steady state operating line. If a good estimate of T40 can be obtained then a temperature regulator can be designed to ensure that maximum temperature limits are not exceeded. The OTKF in the MBEC architecture allows for estimates of this temperature to be taken into account in the control design. The estimates of T40 at both the cruise and takeoff operating condition are shown in Fig. 7. The estimation of T40 is very accurate at both operating conditions and over the engine life cycle, producing only a $1 \%$ error at cruise and $6 \%$ error at takeoff.
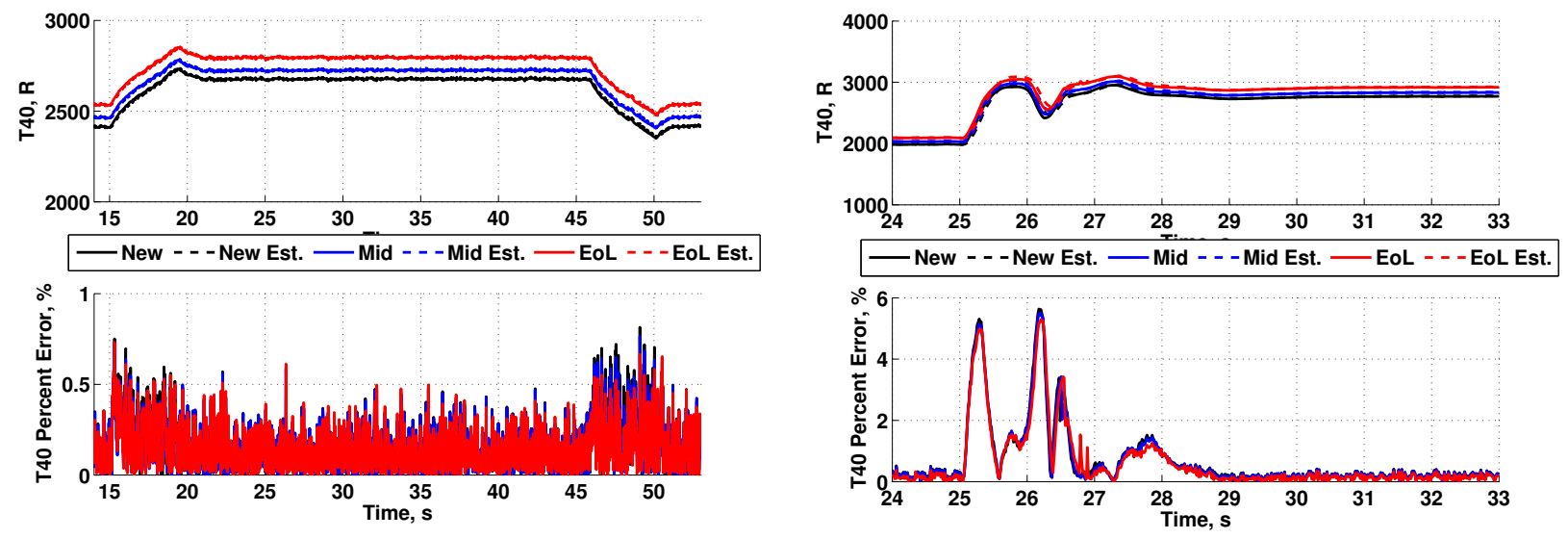

Figure 7. Comparison of the true and estimated T40 over the engine life cycle at cruise (left) and takeoff (right) with the respective percent error. 


\section{Stall margin protection logic results}

This section illustrates a performance comparison between the MBEC protection logic using the estimate of the HPC SM and the baseline CMAPSS40k EPR controller using an acceleration limiter. The transient used for the analysis is for a slightly larger transient than the aforementioned FAA requirement. In this section, the full PLA command range is used to illustrate a case where the protection logic is certain to be required for safe operation. The acceleration limiter is designed to have approximately $11 \%$ HPC SM during a large transient to provide enough margin to safely operate even an EoL engine. The margin is obtained from Table 1 by subtracting the transient from the stall margin stack up. The SM limiter regulator replaces the acceleration limit for the MBEC architecture, where a lower value is sought to illustrate improved thrust response. A SM threshold of only a few percent is possible based on the estimation accuracy shown in the previous section, however this lowering of the limit can have a significant impact on other aspects of the engine operation. It was determined for this study that the SM threshold would be lowered to a value of $8 \%$ to prevent the MBEC design from having a higher max T40 than the baseline. In Fig. 8 and 9 the baseline controller response is shown for a new (dashed black), mid (dashed blue) and EoL engine (dashed red). The MBEC controller response is shown in Fig. 8 and 9 for a new (black), mid (blue) and EoL engine (red). The comparison of the two controllers are obtained by first executing the baseline controller to get an initial steady state value of thrust and a final steady state value after the transient to specify the MBEC thrust command set points.
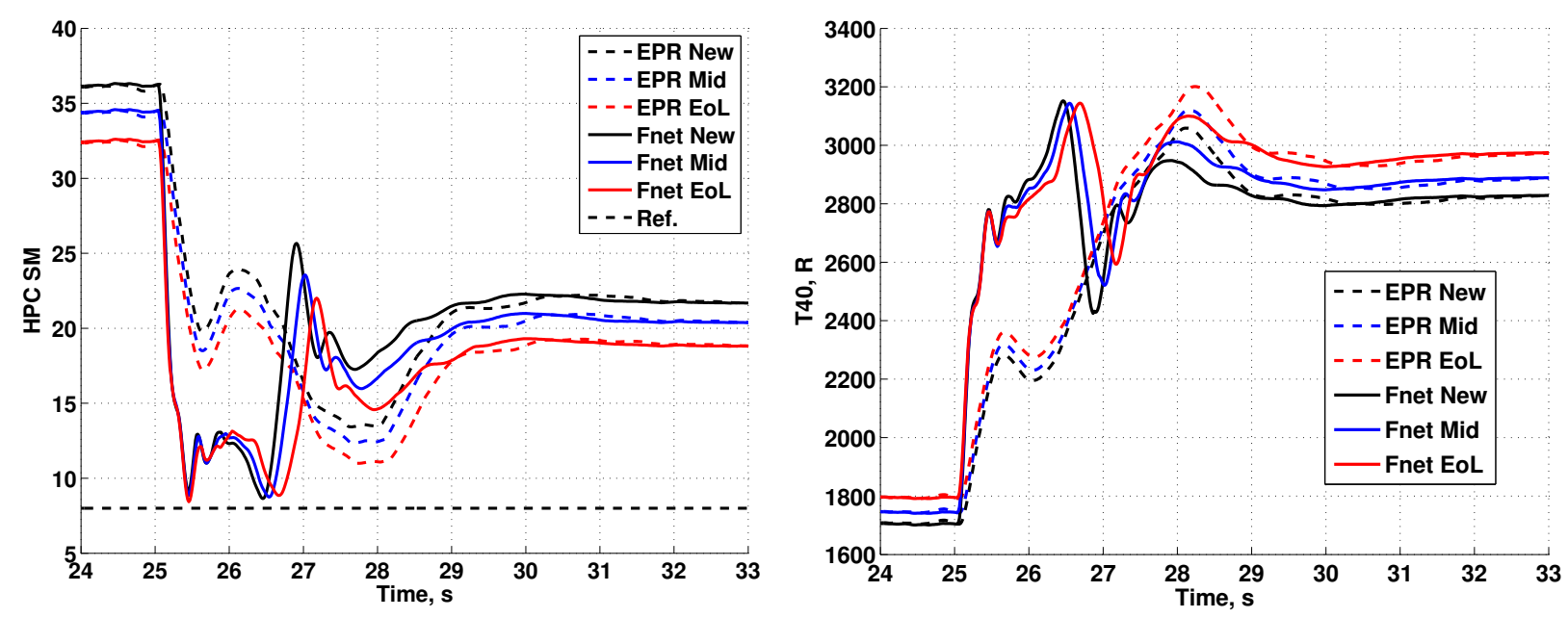

Figure 8. Comparison of the MBEC and baseline controller protection logic over the engine life cycle for the HPC SM (left) and T40 (right).

The estimation of the stall margin shown in Fig. 6 illustrated that the typical deterioration uncertainty in the stall margin stack up can be reduced. For the analysis presented here a SM threshold of $8 \%$ was chosen to provide margin for uncertainty in the estimation and not allow the transient response to significantly exceed the value of T40 for the baseline control architecture. In the results that follow, the estimation error is no longer shown as the approximate percent error of the estimation as was illustrated in the previous section. However, the MBEC controller is still closing the loop on the estimated parameters.

The large transient for this study causes the limiter to engage, which prevents the engine from violating the threshold by limiting the fuel flow. The results shown for the HPC SM in the left plot of Fig. 8 illustrate that both protection logic schemes prevent the engine from surging. However, the MBEC protection logic enables engine operation at a lower level of HPC stall margin as opposed to the conventional core acceleration limit approach, which must apply more conservative logic for an EoL engine. In addition, since the MBEC controller is closed on an accurate estimate of the desired HPC SM parameter, a tighter controller is possible. It is clearly shown in Fig. 8 that the response of the MBEC architecture has less variation during the transient near the limit over the engine life cycle compared to the response of the EPR controller with an acceleration limiter. The right plot of Fig. 8 shows that while the MBEC limiter allows for the HPC SM transient to propagate more freely before the limiter is engaged, the combustor exit temperature peak is approximately 


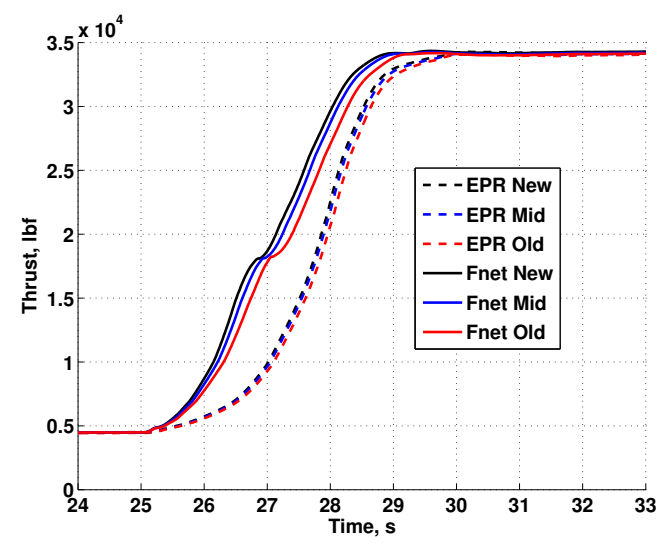

Figure 9. Comparison of the MBEC and baseline controller protection logic over the engine life cycle for the thrust response.

the same as that of the baseline controller.

Since the limiter regulates the fuel flow its design has a large impact on the thrust transient as illustrated in Fig. 9. The MBEC control limiter has a significant response time advantage over the baseline controller using the acceleration limiter. A tight control of the HPC SM is a key potential benefit of the MBEC control design approach. The significance of this, beyond a faster large transient response, would be for the working line of the engine to be allowed to move to a more efficient regime of the operating envelope. This region is typically excluded due to stall margin requirements due to engine life deterioration. If the engine is able to operate more efficiently by the redesign of the working line then the goal of improving the thrust specific fuel consumption can be obtained.

\section{Fan fault and tighter thrust control}

To investigate if the MBEC design could provide a tighter control than the baseline $\mathrm{N}_{\mathrm{f}} / \mathrm{EPR}$ controllers over the engine life cycle, several operating points were investigated. The baseline controller is executed at various deterioration levels and the response of the non-deteriorated engine thrust profile is saved to be used as the thrust command for the MBEC controller design. The general trends from this investigation will be discussed, but the results shown in Fig. 10 are for the previously described cruise operating point and compared to the $\mathrm{N}_{\mathrm{f}}$ baseline controller. The same color scheme for the plotted results are used from the previous section. The MBEC design has less than $1 \%$ error in thrust over the engine life cycle as was shown in Fig. 5. The right plot of Fig. 10 shows that the thrust range for the MBEC design is approximately 60 lbf, while the $\mathrm{N}_{\mathrm{f}}$ control design has a variation of about $90 \mathrm{lbf}$. While the MBEC design here is slightly tighter than the $\mathrm{N}_{\mathrm{f}}$ design, both controllers provide a very tight margin. When comparing other operating points the $\mathrm{N}_{\mathrm{f}}$ design typically had slightly greater thrust variation, but this was not always true for low altitudes. The CMAPSS40k EPR baseline controller always had a smaller thrust variation over the engine life cycle, when compared to the MBEC control design.

The small variation of the thrust over the engine life cycle shown in all of the results, only about $1 \%$, is due to the specific deterioration profile for the CMAPSS40k simulation. The MBEC architecture could potentially provide a tighter thrust control for other engines, where the deterioration is expected to have a greater impact on the thrust output. Previous studies have shown that the deterioration can cause larger thrust variations of up to $3 \% .{ }^{18,19}$ In these cases the MEBC design could provide a significant benefit.

Another area the MEBC control design could provide a benefit is in the case of a fault that would impact the thrust output. A notional fan fault is simulated here, where the fan efficiency and flow capacity is decreased by $3 \%$ at the 25 second mark of a simulation using the cruise operating point profile. The flow capacity drop of $3 \%$ is approximately an order of magnitude larger than a typical decrease in a naturally degraded EoL engine. Here the PLA is held fixed and the transient change is only due to the fan fault. A comparison of the thrust response using the MBEC design to the $\mathrm{N}_{\mathrm{f}}$ baseline controller is shown in Fig. 11. The results show that the fault causes both of the designs to deviate from the commanded set point, but 

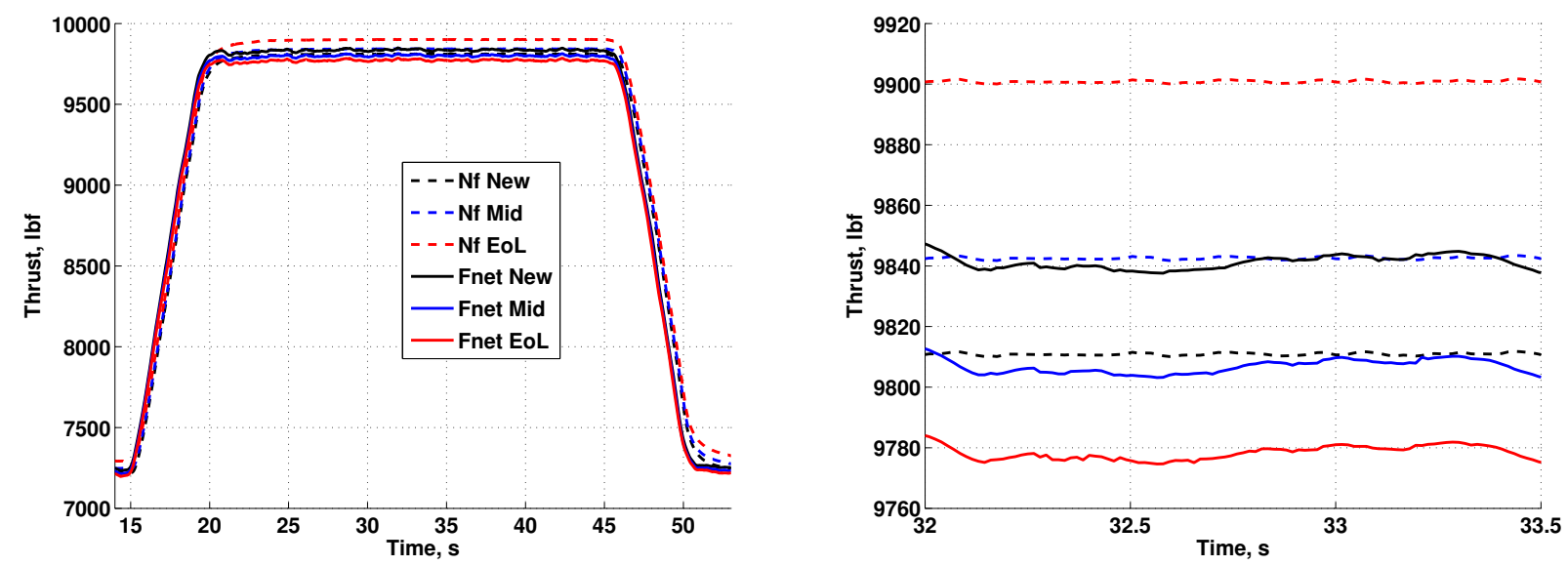

Figure 10. Comparison of the MBEC and $\mathrm{N}_{\mathrm{f}}$ baseline controller to provide a tight control of thrust over the engine life cycle (left) and a zoomed in portion of the thrust response after the initial transient (right).

the MBEC design is impacted to a lesser degree. Note that the MBEC tracks the estimated Fnet, however the on-board model has significant error in estimating Fnet in the pretense of the large fan fault. The use of MBEC to maintain desired performance during faults is an area of ongoing investigation.

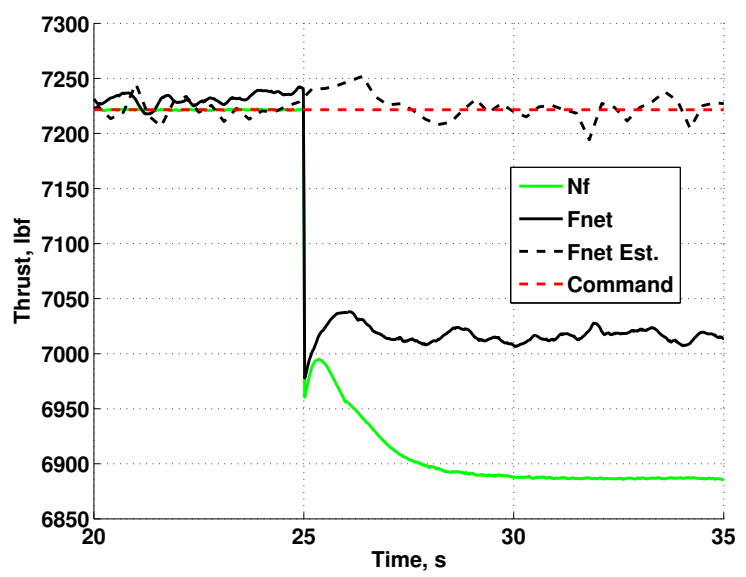

Figure 11. Thrust response comparison of the MBEC control design to $\mathrm{N}_{\mathrm{f}}$ baseline during a fan fault of $3 \%$ reduction in efficiency and flow capacity.

\section{Future Work}

The work presented here illustrated the potential benefit of an MBEC architecture, however to show real efficiency gains a redesign of the engine operating line is required. The MBEC control architecture was shown to open up new areas of the compressor performance map that now can be used to explore more efficient operating conditions. Ongoing work is investigating the efficiency contours of the engine performance maps that can be used to design the new operating line, which will be used to test possible reductions in specific fuel consumption. Since fan faults due to foreign object damage are a relatively common occurrence, the capability to estimate the thrust accurately in the presence of a fan fault needs to be investigated further. Although nothing in this MEBC architecture is adaptive and thus non-deterministic, some means of validating that the estimated values are reasonable will need to be incorporated. 


\section{Conclusions}

The development of a model-based engine control (MBEC) design applied to the Commercial Modular Aero-Propulsion System Simulation 40,000 (CMAPSS40k) turbofan engine simulation and an optimal tuner Kalman Filter (OTKF) estimation routine as the on-board model was shown. The focus was on developing a MBEC design using an OTKF estimation of thrust and high pressure compressor stall margin to replace the baseline turbofan engine feedback control and limiting parameters. The MBEC simulation was shown to provide a tight control bound on thrust over the entire life cycle of the engine. The OTKF provided accurate estimates of the control parameters of interest at cruise and during a large takeoff transient. The most significant result shown is the accurate estimation of the high pressure compressor stall margin. This allowed for the development of a stall margin protection logic that improved the transient response over the baseline control architecture. The MBEC control architecture was also shown to provide a tighter control of thrust in the case of a fan fault.

\section{References}

1 "NASA Fact Sheet: Energy, Efficiency and Emissions." Tech. Rep. NASA/NF-2009-08-488-HQ, NASA, 2009.

${ }^{2}$ May, R., Csank, J., Litt, J. S., and Guo, T., "Commercial Modular Aero-Propulsion System Simulation 40K," Tech. Rep. NASA/TM 2010-216810, NASA, 2009.

${ }^{3}$ Connolly, J., Chicatelli, A., and Garg, S., "Model-Based Control of an Aircraft Engine using an Optimal Tuner Approach," 48th AIAA/ASME/SAE/ASEE Joint Propulsion Conference, No. AIAA 2012-4257, 2012.

${ }^{4}$ Garg, S., Kumar, A., Mathews, H. K., Rosenfeld, T., Rybarik, P., and Viassolo, D., "More Intelligent Gas Turbine Engines," Intelligent Control and Health Monitoring, No. TR-AVT-128, chap. 3, NATO Research and Technology Organization, 2009.

${ }^{5}$ Behbahani, A., Adibhatla, S., and Rauche, C., "Integrated Model-Based Controls and PHM for Improving Turbing Engine Performance, Reliability, and Cost," 45th AIAA/ASME/SAE/ASEE Joint Propulsion Conference, No. AIAA 2009-5534, 2009.

${ }^{6}$ Fuller, J. W., Kumar, A., and Millar, R. C., "Adaptive Model Based Control of Aircraft Propulsion Systems: Status and Outlook for Naval Aviation Applications," ASME Turbo Expo: Power for Land, Sea and Air, No. GT2006-90241, May 8-11 2006.

${ }^{7}$ Lietzau, K. and Kreiner, A., "Model Based Control Concepts for Jet Engines," ASME Turbo Expo: Power for Land, Sea and Air, No. GT2001-0016, 2001.

${ }^{8}$ Brunell, B. J., Viassolo, D. E., and Prasanth, R., "Model Adaptation and Nonlinear Model Predictive Control of an Aircraft Engine," ASME Turbo Expo: Power for Land, Sea and Air, No. GT2004-53780, 2004.

${ }^{9}$ Adibhatla, S. and Gastineau, S., "Tracking Filter Selection and Control Mode Selection for Model Based Control," 30th AIAA/ASME/SAE/ASEE Joint Propulsion Conference, No. AIAA 94-3204, 1994.

${ }^{10}$ Turevskiy, A., Meisner, R., Luppold, R. H., Kern, R. A., and Fuller, J. W., "A Model-Based Controller for Commercial Aero Gas Turbines," ASME Turbo Expo: Power for Land, Sea and Air, No. GT2002 - 30041, 2002.

${ }^{11}$ Henriksson, M. and Ring, D., "Robust Kalman Filter Thrust Estimation in a Turbofan Engine," ASME Turbo Expo: Power for Land, Sea and Air, No. GT2006-91241, 2006.

${ }^{12}$ Ring, D. and Henriksson, M., "Thrust Control for a Turbofan Engine Using Estimation," ASME Turbo Expo: Power for Land, Sea and Air, No. GT2006-91251, 2006.

${ }^{13} \mathrm{Mu}$, J. and Rees, D., "Nonlinear Model Predictive Control for Gas Turbine Engines," ASME Turbo Expo: Power for Land, Sea and Air, No. GT2004-53146, 2004.

${ }^{14}$ Simon, D. L. and Garg, S., "Optimal Tuner Selection for Kalman Filter-Based Aircraft Engine Performance Estimation," Tech. Rep. NASA/TM 2010-216076, NASA, 2010.

${ }^{15}$ Walsh, P. P. and Fletcher, P., Gas Turbine Performance, ASME Press, Blackwell Publishing, NJ, 2nd ed., 2004.

${ }^{16}$ Csank, J., Ryan, M., Litt, J. S., and Guo, T., "Control Design for a Generic Commercial Aircraft Engine," Tech. rep., NASA/TM 2010-216811, 2010.

${ }^{17}$ FAA, "FAR: Title 14 Part 33.73 Power or thrust response," .

${ }^{18}$ Litt, J., Showers, T., and Garg, S., "A Retro-Fit Control Architacture to Maintain Engine Performance," Tech. rep., NASA/TM 2007-214977, 2007.

${ }^{19}$ Brown, H. and Desai, P., "Methods and Apparatus for Estimating Engine Thrust," United States Patent Application Publication - US 2007/0260424 A1, 2007. 

